\title{
CONSTITUCIONALIZACIÓN DEL DERECHO Y CULTURA CONSTITUCIONAL
}

\author{
LUCIO PEGORARO
}


SUMARIO

1. DEFINICIONES. 1.1. «Derecho». 1.2. «Constitución». 1.3. «Constitucionalismo». 1.4. «Cultura jurídica» y «cultura constitucional». 2. CONSTITUCIONALIZACIÓN DEL DERECHO. 2.1. Los códigos, «constituciones» de la burguesía. 2.2. Las constituciones del constitucionalismo y su circulación. 2.3. El ataque al constitucionalismo: el neoconstitucionalismo. 3. LA INTEGRACIÓN DE CULTURAS AUTÓCTONAS EN EL CONSTITUCIONALISMO «FORMAL» Y EL RECHAZO DEL CONSTITUCIONALISMO. 3.1. La resistencia de la tradición. 3.2. El Derecho de derivación divina y divino. 3.2.1 Derecho hindú. 3.2.2. Derecho chino. 3.2.3. Derecho japonés. 3.2.4. Derecho islámico. 3.3. Derecho socialista. 4. CONTRADICCIONES EN EL CONSTITUCIONALISMO Y FRACTURAS ENTRE CONSTITUCIONALISMO Y CULTURAS. 5. LA ENSEÑANZA DE ALGUNAS EXPERIENCIAS SINCRETISTAS. 


\title{
CONSTITUCIONALIZACIÓN DEL DERECHO Y CULTURA CONSTITUCIONAL ${ }^{1}$
}

\author{
LUCIO PEGORARO \\ «;Escuchadme! \\ iA partir de boy \\ el idioma oficial de San Marcos será el sueco!'»
}

Woody Allen’s Bananas (1971)

\section{DEFINICIONES}

Como a menudo se recuerda en la doctrina, un acercamiento analítico a una investigación jurídica presupone, en primer lugar, el análisis de la pregunta a que se quiere responder ${ }^{3}$ : o sea "¿qué significan las palabras «constitucionalización del Derecho y cultura constitucional»?». Hay que analizar, de forma separada y conjunta, los términos «constitucionalización» (y «constitución»/»constitucionalismo»), «Derecho», («cultura jurídica») y «cultura constitucional».

\section{1. «Derecho»}

El primer término es «Derecho»: los comparatistas occidentales liberal-democráticos y constitucionalistas sólo rara vez (o «epidérmicamente») hacen el esfuerzo de aprovechar y aceptar conceptos que son ajenos a nuestra cultura, como el de «amae»

1 Texto basado en la Ponencia presentada en el IV Congreso Internacional sobre Derecho y Justicia Constitucional, «La constitucionalización del Derecho», 19-21 de septiembre de 2018, Santo Domingo (República Dominicana).

2 Catedrático de Derecho público comparado - Departamento de Ciencias políticas y Sociales — Universidad de Bolonia, Profesor afiliado de la Universidad Autónoma de Nuevo León, Profesor en el Doctorado en Derecho, Universidad Libre, Bogotá. luciopegoraro@hotmail.com.

3 Véase, por ejemplo, distintas obras de GuAstini, R., entre ellas (1998). Teoria e dogmatica delle fonti, en Cicu, A., Messineo, F. (eds), Trattato di diritto civile e commerciale, Milano, Giuffrè, passim. 
(armonía) en el Derecho japonés, «fa», «li», «hexie» en el Derecho chino, «dharma» en el Derecho hindú, «ubuntu» o «fanaby maha-olona» (principio de existencia) en el Derecho africano, «sumak kawsay» en el idioma kichwa, pero también «deber», «moral», «religión», «naturaleza», «familia», «tribu», «perdón», «ocio», «tradición», «corrección», «deferencia», «felicidad», etc., que no solo condicionan pre-jurídicamente, sino vertebran el modo de entender lo que nosotros llamamos «Derecho». Es la supremacía del «Occidente jurídico». El jurista occidental no parece entender, en toda su gravedad, los cambios que cada vez más afectan a los fenómenos jurídicos. Prefiere, de hecho, continuar usando una dimensión etnocéntrica de los ordenamientos como una práctica puramente euroatlántica. En otras palabras, le preocupa delimitar y especificar en qué consiste el «Occidente jurídico» y «los argumentos con los que Occidente, máximo artífice [de] la ley global, se enfrenta a otras experiencias y tradiciones jurídicas. Son modalidades y argumentos que a menudo parten del supuesto de que solo nosotros tenemos el Derecho, mientras que los demás solo intentan imitarnos o estúpidamente resistirnos» ${ }^{4}$.

Metodológicamente, la ampliación del concepto de Derecho debería implicar una renuncia al menos parcial del método utilizado en los estudios del Derecho tal como se concibe en nuestra cultura jurídica, y del uso de ciencias aquí consideradas autónomas y distintas, como la sociología o la antropología ${ }^{5}$; implica adaptar el léxico occidental a conceptos casi intraducibles en las categorías jurídicas occidentales ${ }^{6}$; además, eso implica sobre todo resignarnos a aceptar un sentido comparativo de «Derecho» muy amplio, es decir como «normas que limitan el comportamiento humano» ${ }^{7}$, desafortunadamente renunciando a la distinción entre normas «legales» y normas «sociales» o «religiosas». En muchas culturas, la naturaleza cogente de estas últimas prevalece sobre la compulsión de las reglas producidas por el Estado o por otros sistemas de cuya naturaleza «jurídica» nadie se atreve a dudar ${ }^{8}$.

4 Bussani, M. (2010). Il diritto dell'Occidente. Geopolitica delle regole globali, Torino, Einaudi, p. XII.

${ }_{5}$ Para la doctrina sobre el método y el método comparado véase Pegoraro, L. (2014). Diritto costituzionale comparato. La scienza e il metodo, Bologna, Bup, trad. esp. Pegoraro, L., Rinella, A. Derecho constitucional comparado, 1, Pegoraro, L. (2016). La ciencia y el método, Buenos Aires-México, Astrea-Unam, passim; Pegoraro, L., Rinella, A. (2017). Sistemi costituzionali comparati, Torino-Buenos Aires, Giappichelli-Astrea, trad. esp. (2018). Derecho constitucional comparado, 2, Sistemas constitucionales, 2 volúmenes, Buenos Aires-Torino, Astrea-Giappichelli, tomo A, cap. I.

6 A veces se necesitan páginas completas para traducir palabras como «fa»o «li»: v. CAVALIERI, R. (1999). La legge e il rito. Lineamenti di storia del diritto cinese, Milano, Angeli, p. 29 ss.

7 Cfr. Guastini R. (2017). Parte I, cap. V, «Ancora su diritto e forza», § 4, «Il concetto di obbligo giuridico», en ID., Discutendo, Madrid-Barcelona-Buenos Aires-São Paulo, Pons, p. 78.

8 Véase Procida Mirabelli di Lauro, A. (1996). «Prefazione» a Constantinesco, L.-J., Introduzione al diritto comparato, Torino, Giappichelli [trad. it. del libro de Constantinesco, L.-J. (1971). Einführung in die Rechtsvergleichung, I, Rechtsvergleichung, Köln, Heymanns], p. XXXV: «La noción occidental de Derecho es insuficiente para promover una investigación efectivamente macro-comparada, útil para encontrar los arquetips de las categorías». Puede ser extendida a este tipo de acercamiento al Derecho constitucional/público comparado la crítica que Guastini formula a los críticos del realismo: ellos, «aparentemente, no están interesados en (el mero) conocimiento del Dere- 


\section{2. «Constitución»}

El término «constitucionalización» deriva de «constitución» $\mathrm{y}$ «constitucionalismo», a los que otorga un sentido dinámico.

«Constitución» en su significado común significa «la forma en la cual una cosa es constituida», pero este sentido amplio corresponde solo a uno de los significados de «constitución» en el lenguaje jurídico9. Aparte del significado de «constitutio» en el Derecho romano, normalmente se entiende, como significado originario de esta expresión en el lenguaje jurídico moderno, una organización política de tipo liberal y garantista, como la consagrada por el famoso art. 16 de la Déclaration des droits de l'bomme et du citoyen de 1789 ( «Cada sociedad en la cual no estea establecida la garantía de los derechos, ni determinada la separación de poderes, carece de constitución»). No solo forma, pues, sino también sustancia: un mero documento, que sin embargo solemniza la garantía de los derechos y la división de poderes ${ }^{10}$.

La forma caracteriza además otro sentido de «constitución», cuando se hace referencia a un documento solemne, con un nomen a veces diferente ${ }^{11}$, a menudo pero no

cho, y por lo tanto de las prácticas interpretativas que, del Derecho, son una parte constituyente. Lo que les interesa es solo participar en la práctica jurídica «desde el punto de vista interno». Digamoslo así: a la ciencia jurídica definitivamente prefieren la política del Derecho antes que el Derecho. En lugar de describir imparcialmente el Derecho, prefieren (contribuir a) hacerlo» [GUASTINI, R. (2017) «Ermeneutici e analitici», parte II, cap. II, § 4, de ID., Discutendo, cit., p. 225]. Y además: «Una norma fundamental condicionada por una definición de «Derecho» jusnaturalista, claramente no sirve para la descripción de la ley positiva vigente. Solo puede cumplir tareas de política del Derecho: acreditar las normas que se ajustan a la ley natural como vinculantes, desacreditar las normas que no se ajustan a ellas como no vinculantes. El discurso jurisprudencial de los jusnaturalistas no tiene nada genuinamente descriptivo» [ID. (2017). «Problemi concettuali del normativismo», parte I, cap. X, $\S 1$, de ID., Discutendo, cit., p. 126].

${ }^{9}$ Cfr. Dogliani, M. (1994). Introduzione al diritto costituzionale, Bologna, il Mulino.

10 Varias definiciones de constitución en GuAsTINI, R. (1992). Quindici lezioni di diritto costituzionale, Torino, Giappichelli; Mohnhaupt, H., Grimm, D. (2002). Verfassung: Zur Geschichte des Begriffs von der Antike bis zur Gegenwart. Zwei Studien, 2a ed., Berlin, Duncker \& Humblot, trad. it. (2008). Costituzione. Storia di un concetto dall'Antichità a oggi, Roma, Carocci ly varias voces de Pegoraro, L. (ed.) (2009), Glossario di Diritto pubblico comparato, Roma, Carocci, trad. esp. (2012). Glosario de Derecho público comparado (al cuidado de Ferrer MaC-Gregor, E., Nuñez, M., Astudillo, C., Enríquez Fuentes, G., Torres Estrada, E.), México, Porrúa]; Floridia, G.G. (2008). «Qu'est ce-que ... la constitution?», en ID., Scritti minori, Torino, Giappichelli, p. 3 ss. Para un marco general (historia del concepto, doctrinas subyacentes, teorías generales, clasificaciones, etc.) v. MorTati, C. (1962). Voz «Costituzione (Dottrine generali)», Enc. dir., XI, Milano, Giuffrè, p. 132 ss.; Modugno, F. (1977). «Il concetto di costituzione», en AA.Vv., Aspetti e tendenze del diritto costituzionale. Scritti in onore di C. Mortati, 4 volúmenes, Milano, Giuffrè, I, p. 197 ss.; Barile, P., Fioravanti, M. (1992). Voz «Costituzioni». Enc. sc. soc., II, Roma, Ist. enc. it., p. 548 ss.; Fioravanti, M. (1999). Costituzione, Bologna, il Mulino, trad. esp. (2001). Constitución. De la Antigüedad a nuestros días, Madrid, Trotta; GIL, J. (1978). Voz «Costituzione», Enc. Einaudi, IV, Torino, Einaudi, p. 3 ss. En clave politológica Sartori, G. (1995). «Costituzione», en ID., Elementi di teoria politica, 3a ed., Bologna, il Mulino, p. 13 ss.

11 «Estatuto», «Carta», «Grundgesetz» 0 «Ley Fundamental» o, en otras formas de Estado, «Principios Fundamentales» o «Programa común», como en China. 
siempre aprobado con procedimientos especiales, muchas veces con contenidos amplios y genéricos, que siempre conciernen a los poderes, a las relaciones entre órganos del Estado y casi siempre (hoy) también a las relaciones entre autoridad y libertad (es decir, los derechos), con indicación de las finalidades del Estado, exposición de axiologías y decisiones de valores ${ }^{12}$.

Existe además un sentido «sustancial» (y no ideológico) de «constitución», que equivale al conjunto de normas consideradas fundamentales en cada ordenamiento ${ }^{13}$. Cualesquiera que sean las doctrinas inspiradoras y los fines perseguidos, cada sistema tiene su propia constitución. Se entiende entonces por «constitución en sentido sustancial» el conjunto de los actos y hechos normativos a los que la doctrina de un ordenamiento reconoce relevancia constitucional incluyendo, además de la constitución formal, también fuentes que no tienen dicho rango, pero que contribuyen a definir la «materia constitucional», es decir, la estructura fundamental de una comunidad estatal.

El concepto debe mantenerse separado tanto del de «constitución viviente», que es la constitución así interpretada y aplicada por los distintos actores políticos, como del de «constitución material» ${ }^{14}$ : se habla de «constitución material», tanto en el sentido de conjunto de valores fundamentales y no modificables de un sistema, como en el sentido más reducido de núcleo originario derivado de la voluntad política, que no está sometido al Derecho, sino lo crea ${ }^{15}$.

12 Blanco Valdés, R.L. (2012). Voz «Constitución», en Pegoraro, L. (ed.), Glosario de Derecho público comparado, cit., p. $37 \mathrm{~s}$.

13 V. por ej. Lavagna, C. (1985). Istituzioni di diritto pubblico, 6a ed., Torino, Utet, p. 169 ss. [y también Mortati, C. (1975). Istituzioni di diritto pubblico, 9a ed., Cedam, Padova, 2 volúmenes, I, p. 31]. En este sentido, por ejemplo, W. Bagheot escribe The English Constitution, Sir W.I. Jennings The British Constitution, y otros autores, varios manuales de Constitutional Law británico (es decir, de un sistema sin constitución escrita): v. BAGEHOT, W. (1867). The English Constitution, London, Chapman \& Hall, trad. it. (1995). La Costituzione inglese, Bologna, il Mulino; y JenNings, W.I. (1941). The British Constitution, London, Cambridge U.P., Sa ed., reimpr. (1971). Cambridge, Un. Printing House.

${ }_{14}$ Mortati, C. (1940). La costituzione in senso materiale, Giuffrè, Milano. En sus (1975). Istituzioni di diritto pubblico, cit., I, p. 34, Mortati, explica que «no es correcto suponer que una constitución formal, una vez que haya entrado en vigor, resuma totalmente ese conjunto de elementos y factores que se incluyen en el concepto de constitución material, de modo que se les pueda considerar irrelevantes para el estudio del Derecho, y ponerlos en el espacio de lo pre-jurídico», haciendo referencia al concepto de «Derecho viviente» que en sí (es decir, en la eficacia) encuentra legitimación.

15 La formulación más extrema (y conocida) de la constitución como producto de la fuerza y de los cañones, y en consecuencia «trozo de papel», es de Lassalle, F. (1862). «Über Verfassungswesen», en ID. (1919), Gesammelte Reden und Schriften (al cuidado de E. BERNSTEIN), 2 volúmenes, Berlin, Cassirer, p. 38. En este último significado, los comparatistas pueden usar la expresión para estudiar ordenamientos que someten el Derecho a la fuerza, y no la fuerza al Derecho. También Kelsen, H. (1960). Reine Rechtslehre, Wien, Deuticke, cap. V, § 35, let. a, trad. it. (1966). La dottrina pura del diritto, Torino, Einaudi, p. 252, habla de constitución material, pero en el sentido de «regla sobre la producción de reglas». 


\section{3. «Constitucionalismo»}

«El «constitucionalismo» —escribe R. Blanco Valdés— que toma su nombre del principal documento jurídico a través del cual se expresan aspiraciones sociales y políticas del pensamiento liberal (la Constitución), se generalizó, a partir del precedente inglés, como movimiento político e ideológico en la segunda mitad del siglo XviII con el objetivo histórico de superar los elementos constitutivos del absolutismo y con el desafío de construir no solo unos nuevos regímenes políticos sino también una nueva sociedad. Así, frente a la concentración del poder en manos del Rey que caracterizó a las Monarquías absolutas, el movimiento constitucional constituyó los tres Poderes del nuevo Estado liberal (legislativo, ejecutivo y judicial) y proclamó la necesidad de separarlos, equilibrando y coordinando sus funciones respectivas. Además, frente a los privilegios estamentales que definieron durante decenios a la sociedad del Ancien Régime, el constitucionalismo proclamó los derechos del hombre y del ciudadano, comenzando por el derecho que todas las personas tenían a la igualdad ante la ley» ${ }^{16}$.

Una de las claves de esta doctrina está representada por el principio de separación de poderes: este se inspira en gran medida por la exigencia de limitar el poder político concentrado en las manos del Monarca y para proteger la libertad de los individuos $^{17}$. Un segundo factor caracterizador tiene que ver con la garantía de los derechos. Los procesos revolucionarios de finales del siglo XVIII marcaron el fin del Estado absoluto y la afirmación del Estado constitucional de tipo liberal. Estos acontecimientos señalaron, además, la afirmación del constitucionalismo, es decir, aquel conjunto de conceptos y principios que encontraron su expresión más relevante en las cartas constitucionales. El Estado constitucional, pues, funda su legitimación en el reconocimiento de los derechos y libertades fundamentales e inalienables de la persona, así

16 Blanco Valdés, R.L. (2012). Voz «Constitucionalismo», en Pegoraro, L. (ed.), Glosario de Derecho público comparado, cit., p. 40. La literatura es copiosa. Entre otros, v. McIlwaIN, C.H. (1947, 1a ed. 1940). Constitutionalism: Ancient and Modern, Ithaca, Cornell U.P., trad. it. (1956 y 1990). Costituzionalismo antico e moderno, Vicenza-Venezia, Neri Pozza, y Bologna, il Mulino; WormutH, F.D. (1949). The Origin of Modern Constitutionalism, New York, Harper \& Row; GougH, J.M. (1955). Fundamental Law in English Constitutional History, Oxford, Clarendon; MatTeucci, N. (1976). Organizzazione del potere e libertà. Storia del costituzionalismo moderno, 3a ed., Torino, Utet; ID. (2004). Voz «Costituzionalismo», en Bobbio, N., Matteucci, N., Pasquino, G. (eds), Il dizionario di politica, 3 a ed., Torino, Utet, p. 226 ss., y en Matteucci, N. (1993). Lo Stato moderno: lessico e percorsi, Bologna, il Mulino, p. 127 ss.; LuTz, D.S. (1988). The Origin of American Constitutionalism, Baton Rouge, Louisiana State U.P.; JimÉNEZ Asensio, R. (2001). El constitucionalismo, Oñati, Ivap; Griffin, S.M. (1996). American Constitutionalism: From Theory to Politics, Princeton, Princeton U.P., trad. it. (2003). Il costituzionalismo americano. Dalla teoria alla politica, Bologna, il Mulino, y BognetTI, G. (1998 y 2000). Lo spirito del costituzionalismo americano, I, La Costituzione liberale, y II, La Costituzione democratica, Torino, Giappichelli. Reflexiones útiles en Glaser, H. (ed.) (2015). Norms, Interests, and Values: Conflict and Consent in the Constitutional Basic Order, Baden-Baden, Nomos, p. 9, centrado sobre «the foundational consensus manifested in the constitutional basic order».

17 Véase Bognetti, G. (1994). La divisione dei poteri, Milano. Giuffrè. 
como sobre la codificación de instituciones e instrumentos idóneos para poner límites al poder político.

Sin embargo, el programa del constitucionalismo sufrió reacciones, frenos, bloqueos, correcciones y negaciones. Como recuerda Blanco Valdés, «No es casual, a la vista de ese contraste entre los principios proclamados y la realidad efectiva del constitucionalismo y a la vista, igualmente, del hecho de que el Estado constitucional será originariamente una realidad histórica restringida a un reducido grupo de países, que la evolución del constitucionalismo fuera a producirse durante los siglos XIX y XX en una doble dirección: por un lado, en el de la extensión geográfica del fenómeno constitucional; por el otro, en el del progresivo perfeccionamiento de los mecanismos jurídicos y políticos destinados a garantizar la eficacia de los dos principios basilares del constitucionalismo: la libertad y la igualdad» ${ }^{18}$.

\section{4. «Cultura jurídica» $y$ «cultura constitucional»}

Para definir el sentido de «cultura constitucional», es necesario definir previamente el significado de «cultura jurídica». El comparatista debe plantearse el interrogante de si y cuándo el formante cultural pertenece a la esfera de lo jurídico, al menos en aquellos ordenamientos que no aceptan el Derecho occidental ${ }^{19}$. En la composición de los elementos de evaluación entran también factores apreciables no sólo desde una perspectiva jurídica (occidental), sino también histórica, económica, sociológica ${ }^{20}$.

18 Blanco Valdés, R.L. (2012). Voz «Constitucionalismo», cit., p. 42. La búsqueda de un punto de equilibrio entre la libertad de los individuos y la autoridad del poder público ha evolucionado en la historia, a través de la evolución de las cartas constitucionales y de los principios que forman su columna vertebral: la afirmación de los derechos y libertades fundamentales, la autonomía del individuo y de la sociedad civil hacia el Estado, la separación de poderes y las instituciones democráticas, el principio de legalidad, la afirmación del valor primario de la ley como expresión de la voluntad general, la reserva de ley, etc.

19 Sobre la existencia de una tradición jurídica occidental BERMAN, H.J. (1983). Law and Revolution: The Formation of the Western Legal Tradition, Cambridge, Harvard U.P., trad. it. (1998). Diritto e rivoluzione. Le origini della tradizione giuridica occidentale, Bologna, il Mulino; Kelly, J.M. (1992). A Short History of the Western Legal Theory, Oxford, Clarendon. MonATERI, P.G. (2013). Geopolitica del Diritto, Genesi, governo e dissoluzione dei corpi politici, Roma-Bari, Laterza, critica a Berman, quien habría reducido todo Occidente (europeo) al estadounidense.

${ }^{20}$ Sobre el debate relativo al uso de la cultura juridíca y de la cultura en general como paradigma de comparación, véase CotTERELl, R. (2006). «Comparative Law and Legal Culture», en REIMANN, M., Zimmermann, R. (eds), The Oxford Handbook of Comparative Law, New York, Oxford U.P., 709 ss. Ivi, p. 717 ss., p. 725 ss., algunas consideraciones sobre la dificultad (pero no imposibilidad) de definir qué es «cultura» (jurídica o no). Véase también RiLes, A. (2006). «Comparative Law and Socio-Legal Studies», ivi, p. 796 ss., que menciona (y critica) la concepción de Weber (de cultura en términos «general and quite totalizing» — p. 802) y la observación de P. Glenn que «antropologists since the 1960s universally reject a concept of culture as an integrated, totalizing whole» (p. 798). Sobre los formantes metajurídicos («Metalegal Formants»), en el marco de un «common core 
La cultura jurídica representa el resultado de los que Rodolfo Sacco llama «formantes» del ordenamiento: expresión utilizada para indicar los diferentes conjuntos de reglas y proposiciones que, en el ámbito del ordenamiento, contribuyen a generar el orden jurídico de un grupo, en un lugar y en un momento determinados ${ }^{21}$.

En los ordenamientos contemporáneos, los formantes principales son: la ley, la doctrina y la jurisprudencia; es decir, el conjunto de disposiciones adoptadas por el legislativo; el conjunto de opiniones expresadas por los expertos; y el conjunto de decisiones de los jueces ${ }^{22}$. Sin embargo, existen también formantes que, a diferencia de los mencionados, no resultan de fórmulas enunciadas de modo expreso. Sacco define como «criptotipos» a aquellos modelos implícitos que están presentes en los diversos sistemas jurídicos y que actúan de forma penetrante en la demostración y decisión de cuestiones jurídicas. Aun cuando no están enunciados expresamente se perciben y transmiten entre generaciones de juristas y «asumen, para quien los usa, el carácter de cosa “obvia" ». Normalmente, un jurista que pertenece a un sistema determinado tiene mayor dificultad en librarse del conjunto de «criptotipos» presentes en su sistema, que en abandonar la regla de la que es plenamente consciente. «Tal sujeción a los “criptotipos" constituye la «mentalidad» del jurista de un determinado país. Y la diferencia de mentalidad representa el principal obstáculo a la comprensión entre juristas de procedencia territorial diferente, algo que solamente se puede obviar con el ejercicio de la comparación a nivel sistemático e institucional» ${ }^{23}$.

Para definir «cultura jurídica», pues, es fundamental centrarse en el papel de la doctrina (y su sensibilidad frente a los criptotipos) aunque hoy, en el mundo occiden-

approach», véase Bussani, M., Mattei, U. (1997). "The Common Core Approach to European Private Law». Columbia law journ. eur. law, n. 3, p. 339 ss. y «Appendix 1». De Bussani, M., MATTEI, U. (eds) (2002) véase también The Common Core of European Private Law - Essays on the Project, The Hague-London-New York, Kluwer Law International. En particular, sobre constitución y cultura, DA SIlva, J.A. (2009). "Constituição e cultura», en AA.VV., Memoria del X Congreso iberoamericano de Derecho Constitucional, 2 volúmenes, Lima, Inst. Iberoam. de Der. Const. et al., I, p. 555 ss.; CARBOnell, M. (2006). "Constitucionalismo y multiculturalismo», en PÉrez Royo, J., Urías Martínez, J.P., Carrasco Durán, M. (eds), Derecho constitucional para el siglo XXI, 2 volúmenes, Cizur Menor, Thomson-Aranzadi, II, p. 4757 ss.

21 Sacco, R. (1991). «Legal Formants: A Dynamic Approach to Comparative Law». Am. journ. comp. law, n. 2, p. 343 ss.; ID. (1992). Introduzione al diritto comparato, 5a ed., Torino, Utet, p. 43 ss. Como lo recuerdan Bussani, M., Mattei, U. (2002). «The Common Core Approach to European Private Law», cit., p. 339, «a list, even an exhaustive one, of all the reasons given for the decisions made by the courts is not the entire law. Neither are the statutes the entire law, nor are the definitions of legal doctrines given by scholars. In order to know what the law is, Sacco's reasoning continues, it is necessary to analyze the entire complex relationship among what he calls the 'legal formants' of a system. (...) All these formative elements are not necessarily coherent with each other within each system».

22 Análogamente en este sentido, Zitelman, E. (1900). «Aufgaben und Bedeutung der Rechtsverleichung». Deutsche Jur.-Zeit., V, p. 329, para el cual los tres campos de actividad jurídica son la praxis, la investigación y la creación (o normación).

23 SACCO, R. (1992). Introduzione al diritto comparato, cit., p. 128. 
tal, no produce directamente Derecho autoritativo ${ }^{24}$. Es necesario entonces alejarse de la visión del positivismo legislativo — defensor de la «univocidad de la regla»— a favor de una visión (también positivista) del Derecho que dé a cada formante su papel, según los tiempos y lugares.

Éste nos permite introducir la cuestión de la fractura entre «cultura jurídica»y «cultura constitucional». Esta expresión adquiere hoy valores y caracteres «favorables», igual que la palabra «constitución» en el artículo 16 de la Declaración ${ }^{25}$. No es científicamente neutral. «Cultura constitucional» es la cultura jurídica que acepta, vive, venera la superioridad de la constitución, pero no cualquier constitución, sino solo la que acepta la división de poderes (poco) y sobre todo los derechos humanos, en sus interpretaciones más radicales hasta rechazar la democracia, la voluntad popular, el Estado, el propio Estado de Derecho, confiando en un poder —el judicial y de

${ }^{24}$ Pero no ha sido siempre así en el pasado, ni así es hoy en cualquier sitio: en el Derecho romano, y hasta la revolución francesa (e incluso más tarde, en Alemania, gracias a la Pandectística y en Andorra hasta 1993), la doctrina también creaba Derecho: la manifestación más clara de ello fue la «Ley de las citas», con la cual en 426 d.C. Teodosio II creó una suerte de Stufenbau de las opiniones de los juristas, con en el vértice de la jerarquía a Pablo, Ulpiano, Gaio, Modestino y otros, y criterios para resolver las antinomias. El Derecho hindú se basa todavía ampliamente (aunque de forma recesiva) en las interpretaciones de los doctos recopiladas entre los siglos XII y XVII en los nibandhas, comentarios del Manusmrti, o «Código de Manu». [Véase al menos Menski, W.F. (2003). Hindu Law: Beyond Tradition and Modernity, New Delhi, Oxford U.P.; Lingat, R. (1973). The Classical Law of India, Berkeley, Un. of California Press; ID. (1967). Les sources du droit dans le système traditionnel de l'Inde, La Haya, Mouton \& Co., trad. it. (2003). La tradizione giuridica dell'India, Milano, Giuffrè; Diwan, P. (1993). Modern Hindu Law, 9. ${ }^{a}$ ed., Allahabad, Allahabad Law Agency. Una síntesis eficaz de las fuentes de ese Derecho se encuentra ahora en Amirante, D. (2012). Voz «Derecho hindú y Derecho indio», en Pegoraro, L. (ed.), Glosario de Derecho público comparado, cit., p. 116 ss.; ID. (2013 y 2013). «Il caleidoscopio del diritto indiano: percorsi di comparazione». Rev. gen. der. públ. comp., n. 14, p. 1 ss., y Ann. dir. comp. st. legisl. 2013, p. 239 ss.; ID. (2014). Lo Stato multiculturale. Contributo alla teoria dello Stato dalla prospettiva dell'Unione Indiana, Bologna, Bup]. El Derecho musulmán, que vincula a 1.300 millones de personas, tiene entre sus fuentes la ijma, es decir, la opinión acorde de la comunidad (sunnita, no chiita) de los juristas-teólogos, o al menos de los más destacados, a condición de que esté muy difusa y formulada claramente. Véase Losano, M.G. (2000). I grandi sistemi giuridici. Introduzione ai diritti europei ed extraeuropei, Bari, Laterza, p. 387 ss. Como nos recuerda Oliviero, M. (2012). Voz «Derecho islámico», en Pegoraro, L. (ed.), Glosario de Derecho público comparado, cit., p. 120 ss., «La ciencia del Derecho islámico (ilm'al-fiqh) se divide en dos grandes partes. Por un lado, se compone por las «raíces» (usül al-fiqh) que explican por medio de qué procedimientos y qué fuentes ha sido hallado el conjunto de disposiciones que constituyen la Shari`a. Son consideradas «raíces»: el Corán (Qur'ān), la sunna (sunnat al-nābī), el consenso $(\overline{i g} m \bar{a})$ y la analogía (qiyās). Por otro lado, se encuentra constituida por las «ramas» (furu al-fiqh) de la jurisprudencia. Los furū, considerados por los doctos de las leyes ('ulamā) como derivados de la primera división, comprenden algunas materias que, utilizando las modernas categorías jurídicas occidentales, constituyen el Derecho privado, el Derecho penal, el Derecho procesal y parte del Derecho público».

25 Véase sobre todo los 4 volúmenes de Lucas, C. (ed.) (1988). The French Revolution and the Creation of Modern Political Culture, Pergamon Press, Oxford et al.; desde una perspectiva occidental, HäBERLE, P. (1988). Verfassungslehre als Kulturwissenschaft. (Schriften zum Öffentlichen Recht), 2a ed., München-Leipzig, Duncker \& Humblot, trad. it. (2001). Per una dottrina della costituzione come scienza della cultura, Carocci, Roma; ID. (2006). Costituzione e identità culturale. Tra Europa e Stati Nazionali, Giuffrè, Milano. 
control de la constitucionalidad, estructurado en los siglos pasados para proteger estos valores-, para imponer un «núcleo ético esencial» que orienta esos valores, los limita y a veces incluso los anula.

Entonces, la cultura jurídica constitucional de hoy pasa a través de la constitucionalización del Derecho, en la medida en que hace de la constitución (y su «doctrina») un elemento esencial del Estado de Derecho.

\section{CONSTITUCIONALIZACIÓN DEL DERECHO}

Desde una perspectiva interna, la expresión «constitucionalización del Derecho» tiene un sentido esctricto: la interpretación tradicional es que la constitución permea cualquier rama del Derecho de cada ordenamiento: civil, penal, laboral, mercantil, financiero, etc., interpretados conforme al léxico y los «valores» de la propia constitución. A su vez, la «cultura constitucional» sería la cultura que acepta y defiende la superioridad de la constitución: por supuesto, si tiene los contenidos que hemos mencionado con anterioridad.

Además de la lectura interna existe una comparada. «Derecho» no es el Derecho de cada ordenamiento estatal (occidental), y cultura no es (solo) la cultura de la Ilustración. La palabra «constitucionalización» entonces tiene que ver con la exportación de esas teorías, a las cuales otorga un sentido universal. Sin embargo, las constituciones no son ajenas al sistema jurídico en el cual están engarzadas: las cartas constitucionales - ya sea en el caso en que supongan una ruptura con el ordenamiento precedente, ya sea en el caso en que sean una evolución - reflejan (en todo o en parte) los rasgos característicos del sistema jurídico en el contexto del cual se erigen como parámetro supremo de referencia. Las ideas y valores que inspiran el nacimiento de una constitución cambian respecto del viejo régimen; sin embargo, la nueva constitución debe ajustarse necesariamente a un marco jurídico de relaciones, restricciones, facultades, libertad, obligaciones etc., que en general sobrevive al nacimiento de la nueva constitución. La constitución diseña las relaciones entre autoridad y libertad; establece los aspectos organizativos fundamentales del ordenamiento de las autoridades públicas y formula los principios y criterios para salvaguardar las libertades de los individuos. Por lo demás, se integra en un contexto jurídico que dista mucho de ser una tabula rasa. En otras palabras, cada constitución debe hacer las cuentas con el sistema jurídico preexistente: este en parte resistirá a la llegada del nuevo orden constitucional, en la medida en que resultará compatible con él; en parte se enfrentará a derogaciones por incompatibilidad o al menos reinterpretaciones.

Los sistemas de fuentes están hoy prevalentemente condicionados y gobernados por la constitución, que afecta su estructura no solo si la comparamos con el Estado decimonónico, sino también en las familias y formas de Estado no occidentales y/o no liberal-democráticas (con fuertes bases consuetudinarias, jurisdiccionales/doc- 
trinales, teocráticas). A pesar del ataque que incluso la constitución sufre hoy, por parte de fuentes supranacionales o transnacionales (y las corrientes neoconstitucionalistas), cualquier discurso sobre las fuentes (y sobre el Derecho) no puede entonces prescindir de un discurso sobre la constitución. Esta representa, por un lado, el elemento de cambio más visible respecto a la sistematización de las fuentes del siglo XIX; por otro lado, incluso y sobre todo, la defensa más fuerte (aunque a veces no efectiva) hacia las «otras» formas de pensar el Derecho: tanto el el Derecho producido por entidades supra o trans-estatales, como el Derecho con base tradicional, «exportado» a veces hasta fuera de las regiones donde se encuentra normalmente; como el Derecho occidental en áreas donde las constituciones mantienen un espacio para las concepciones tradicionales ${ }^{26}$.

En este sentido se puede entonces hablar de una «constitucionalización del Derecho» que se da entre la época de las codificaciones y la actual, de la internacionalización del Derecho, donde la idea de «constitución» permanece, aunque privada de muchos contenidos, a favor del concepto de híper-constitución y del Derecho convencional.

Todas estas fases están marcadas por un ineluctable carácter eurocéntrico, expansionista y doctrinariamente «imperialista», que da por hecha la alineación entre formante jurídico-constitucional y formante cultural (en el constitucionalismo clásico), o al revés lo sacrifica a favor del formante jurisprudencial/internacional (hoy).

\subsection{Los códigos, «constituciones» de la burguesía}

La «constitucionalización del Derecho» no se daba todavía en la época de los códigos elaborados tras la Revolución Francesa ${ }^{27}$ : las «verdaderas» constituciones de aquella época, en efecto, eran no tanto (o no solo) los documentos por lo general bre-

26 Sobre los graves problemas epistemológicos que conlleva el estudio del Derecho constitucional comparado cuando se refiere a «otros» Derechos véase ahora, con un enfoque basado en el respeto a los demás y ya no en la tolerancia, SBAilò, C. (2017). «Per un approccio concreto ed ermeneuticamente orientato al costituzionalismo islamico contemporaneo», en BAGNI, S., Figueroa Mejía, G., Pavani, G. (eds.), La ciencia del derecho constitucional comparado. Estudios en bomenage a Lucio Pegoraro, 3 volúmenes, México, Tirant lo Blanch-México, I, p. 673 ss.; GArAY Montañez, N. (2017). «Lo decolonial y su influencia en el derecho constitucional», ivi, I, p. 991 ss.; CARDUCCI, M. (2017). «'Ragione politica' della comparazione e "costituzionalizzazione” delle tassonomie». Dir. pubbl. comp. eur., n. 4, p. 1097 ss.

27 Lo que distingue las consolidaciones y las codificaciones antiguas (el Código de Hammurabi, el Decálogo de la Biblia, las Doce Tablas, el Código de Justiniano, etc.) y las posteriores, hasta el siglo XVIII, de los códigos elaborados después de la Revolución francesa, es que estos ultímos, rechazando la supervivencia del jus commune y de los Derechos particulares, con base en de las ideas del iusnaturalismo racionalista, del iluminismo o del iuspositivismo, pretenden modificar funditus el sistema de fuentes, y no solo racionalizar las fuentes existentes en una compilación dirigida a hacerlas más conocibles. 
ves, flexibles y «concedidos» por los Monarcas a la burguesía reunida en los nuevos Parlamentos, sino — como se ha dicho- justamente el corpus de los códigos ${ }^{28}$.

Al principio el producto creado es unívoco y compacto. Las fuentes son aquellas nuevas, los códigos; el Parlamento es el sujeto que genera las fuentes; la nueva clase social representada en el Parlamento toma, en aquella sede, los propios derechos de autonomía (de darse reglas), de libertad (de ser protegida de los abusos de los soberanos), de dominio (de disfrutar la propiedad). Hay conexiones recíprocas, no solo entre estas categorías de derechos, sino también entre derechos, lugar de producción (el Parlamento), forma de producir (la ley, el código), ideología (liberalismo). Los distintos fragmentos (componentes) del Derecho constitucional son por tanto coherentes, solo hasta cuando — en cada Estado- hay equilibrio entre economía, cultura y Derecho, y solo hasta donde el Derecho es expresión de las mismas exigencias económicas y culturales (el mundo occidental de la revolución burguesa) ${ }^{29}$.

Las codificaciones francesa, alemana y suiza representaron los modelos de una recepción de alcance ecuménico ${ }^{30}$. Sin dejar de influir en los países objeto de la conquista napoleónica, como Suiza, Italia, los Países Bajos y Bélgica, los códigos franceses fueron exportados a otras regiones de Europa y del mundo ${ }^{31}$.

28 Paladin, L. (1996). Le fonti del diritto italiano, Bologna, il Mulino, p. 29; v. también Pegoraro, L., Rinella, A. (2018). Derecho constitucional comparado, 2, Sistemas constitucionales, cit., tomo A, p. 316 ss.

29 Como destacan Palermo, F., Nicolini, M. (2014). «La semantica delle differenze e le regole diseguali: dall'egualitarismo nel diritto all'eccezione culturale», en AA.Vv., Studi in onore di Maurizio Pedrazza Gorlero, 2 volúmenes, Napoli, Esi, I, I diritti fondamentali fra concetti e tutele, p. 523, «Nello Stato censitario e monoclasse, la borghesia, per un verso, si avvantaggia dell'affrancamento del capitale e del patrimonio dagli ormai aboliti vincoli feudali e corporativi; per altro verso, percorre, senza soluzione di continuità, il circuito della rappresentanza politica, dove i rappresentanti, espressione della medesima classe dei rappresentati, decidono a maggioranza, elevando, sotto il velo dell'eguaglianza, un interesse 'proprio' a volontà di tutti i consociati». Cfr. además PEdrazza Gorlero, M. (2012). Il patto costituzionale. Potere e diritto fra protezione ed obbedienza, 2a ed., Padova, Cedam, p. 163: «l'autore della costituzione ... è ... la borghesia, cioè la medesima classe politica che, attraverso i suoi rappresentanti eletti nel Parlamento, delibera le leggi». Lo que explica por qué las «normas sobre las fuentes», en época liberal, se encuentran en las «Disposiciones sobre la ley en general» preliminares al código civil, y el «rilievo costituzionale allora spettante al Codice stesso», «Carta fondamentale della borghesia»: véase PALADIN, L. (1996). Le fonti del diritto italiano, cit., p. 29. Sobre el Estado monoclase cfr. Giannini, M.S. (1986). Il pubblico potere. Stati e amministrazioni pubbliche, Bologna, il Mulino, p. 35 ss.; Ridola, P. (2006). Diritti fondamentali. Un'introduzione, Torino, Giappichelli, p. 72.

${ }^{30}$ Los territorios restaurados después de la caída de Napoleón asistieron casi todos a repentinas abrogaciones de los códigos franceses allí introducidos y al momentáneo resurgimiento del jus commune; pero su evidente inadecuación, la difusión de la cultura iluminista, las exigencias de unificación del Derecho, las presiones de los movimientos liberales, indujeron a los distintos príncipes a proceder a nuevas codificaciones (cuando no se conservó simplemente el Code civil).

31 V. en general Monateri, P.G., Somma, A. (2009). Il modello di civil law, 3a ed., Torino, Giappichelli. 
Inmunes a los influjos del common law, en el curso del siglo XIX todos los Estados latinoamericanos, que apenas acababan de alcanzar la independencia, consideraron indispensable dotarse de códigos y superar el Derecho basado en las Leyes de Indias, las llamadas Siete Partidas (América española) o las Ordenaçoes Filipinas (Brasil). Allí, la codificación habló francés por la imposibilidad de utilizar otros modelos, en particular los de los países de lengua materna —España y Portugallos cuales no solo representaban la antigua potencia colonial, sino que carecían de códigos civiles respectivamente hasta 1889 y 1867 , cuando se proveyeron de los mismos imitando el prototipo napoleónico. Al mismo tiempo, otras experiencias dan testimonio del exitoso intento de implantar en el corpus del «ultraocéano» institutos propios del Derecho indígena ${ }^{32}$. Después de mediados del siglo, los códigos franceses fueron contemplados también en el Norte del continente, por Luisiana, Quebec y hasta por California y Dakota; así como, después de la descolonización, por las ex-colonias francesas y por Somalia y Etiopía. En los territorios musulmanes, sin embargo, la implantación de los códigos franceses ocasionó problemas por la enorme distancia que separaba, y continúa separando, las concepciones filosóficas, culturales, religiosas y las condiciones políticas, económicas y sociales de Occidente respecto a las del mundo islámico y del Derecho por él expresado: era fatal que un Derecho rígido manifestase oposición hacia las instancias de renovación ${ }^{33}$.

Los códigos alemanes y, en particular, el $B G B$, no fueron nunca objeto de recepciones pasivas, pero su influencia fue notable en Japón y en China (código de 1929); en Brasil y en Perú; en Hungría, Yugoslavia, Checoslovaquia y en Grecia. A su vez, el código civil suizo no solo representó una piedra miliar de la modernización turca emprendida por Mustafa Kemal $(1927)^{34}$, sino que también llegó a influenciar a numerosos países de Europa Oriental ${ }^{35}$, de Sudamérica ${ }^{36}$ y de Asia ${ }^{37}$.

No obstante las numerosas crisis de rechazo que la codificación sufrió, bien en Europa (especialmente en los países germánicos), bien más tarde en países declarados independientes ${ }^{38}$, el modelo codificado hunde por todas partes firmes raíces.

32 Véase ahora Lanni, S. (2017). Il diritto nell'America Latina, Napoli, Esi, p. 55 ss.

33 Que sin embargo fueron perseguidas en otras ocasiones: en el Imperio otomano, donde la Ley de las Capitulaciones, que aseguraba la aplicación del Derecho occidental a los europeos, había favorecido una parcial familiarización de varios sistemas jurídicos, la influencia francesa se traduce en un código comercial en 1850 y en un código penal en 1858. Así también, en el curso del siglo XIX se proveyeron de códigos Túnez, Argelia y Egipto.

34 Losano, M.G. (1985). L'ammodernamento giuridico della Turchia (1839-1926), 2a ed., Milano, Unicopli.

35 URSS — código civil de 1923—, Checoslovaquia, Hungría y Polonia.

36 En especial el código civil de Perú.

37 Siam y China.

38 En particular donde la raíz del Derecho consuetudinario, jurisprudencial y religioso obstaculizó su aplicación. 
El acuerdo perfecto entre código y sociedad de su tiempo empezó a romperse incluso en Occidente apenas el programa liberal expresado por él se demostró insuficiente para afrontar la nueva misión que el Estado se proponía en el campo social ${ }^{39}$. La crítica a los códigos proviene, bien de los componentes políticos que reputaban inadecuadas las «gotas de aceite social» a veces incluidas en el texto, bien de la Iglesia, de la doctrina o de la jurisprudencia, llamada a interpretar los códigos y que alcanza a reivindicar con la Freirechtsschule - Escuela del Derecho libre - un papel creativo. Fue, sin embargo, el mismo legislador el que propinó el decisivo golpe al modelo codificador, en el que el Estado liberal se reconocía ${ }^{40}$. Al final del siglo Xıx y, sobre todo, después de la Primera Guerra Mundial, la legislación laboral, aseguradora, previsora sobre los alojamientos, etc., viene a afincarse y a sobreponerse a los códigos, formando un cuerpo de leyes especiales, con las que los Parlamentos querían satisfacer las necesidades de nuevas clases y de grupos particulares $^{41}$. Clases y grupos que buscaban amparo en un documento - la constitución- llamado a fijar las reglas del juego, y por tanto más «rígido» que la ley aprobada por las mayorías simples.

\subsection{Las constituciones del constitucionalismo y su circulación}

La colonización implantó sobre cuerpos normativos autóctonos, con legitimación tradicional o divina, formas de producción del Derecho derivadas de los arquetipos occidentales, los códigos (o, en el common law, un Derecho con base jurisprudencial). A ello se ha acompañado o le ha seguido la fase de la exportación de las constituciones.

Ya en el periodo revolucionario, el reconocimiento mismo de la existencia de derechos naturales no podía más que producirse en su afirmación positiva y en la enunciación de reglas que garantizaran su ejercicio: la fuente por excelencia, la ley, venía llamada a rediseñar el Derecho civil y, a la vez, aunque con un nombre diferente —el de constitución — venía a delimitar el poder del Monarca, a reestructurar el Estado y a establecer los límites de la administración pública. El Derecho constitucional, en suma, nace como Derecho formalmente legislativo.

39 KLeiN, F. (1911). «Die Lebenskraft des Allgemeinen bürgerlichen Gesetzbuches», en AA.Vv., Festschrift zur Jabrhundertfeier des Allgemeinen Bürgerlichen Gesetzbuches, 1. Juni 1911, Wien, Manz, p. 3 ss. Sobre la crisis de la ley, v. Lopez de OÑATe, F. (1942, reimpr. 1968). La certezza del diritto, Milano, Giuffrè; Forsthoff, F. (1964). Rechtsstaat im Wandel, Stuttgart, Kohlhammer, trad. it. (1973). Stato di diritto in trasformazione, Milano, Giuffrè; Porras Nadales, A.J. (1988). Introducción a una teoría del Estado post-social, Barcelona, Ppu. Desde la perspectiva de ciencia de la administración, LA SpINA, A., Majone, G. (2000). Lo Stato regolatore, Bologna, il Mulino.

40 Wieaker, F. (1974). Industriegesellscahft und Privatrechtsordnung, Frankfurt a.M., Athenäum Fischer, trad. it. (1983). Diritto privato e società industriale, Napoli, Esi.

${ }^{41}$ IRTi, N. (1999). L'età della decodificazione, 4a ed., Milano, Giuffrè. 
Posteriormente, la constitución presenta forma y contenidos distintos. Forma, porque se vuelve en rígida; contenido, porque incorpora los derechos y libertades, es decir la forma de Estado.

La rigidez del texto a través de cláusulas especiales representó la necesidad de recomponer los intereses en conflicto, no sujetados a la regla habitual de la mayoría simple del Parlamento. La flexibilidad, por el contrario, manifestaba la indiferencia de un poder, monolíticamente representado en el Parlamento, para utilizar procedimientos diferentes a los de la ley ordinaria para deliberar en las instancias políticas. Esto explica cuáles son las razones por las que las constituciones rígidas se imponen: para tutelar, en los ordenamientos federales, a los Estados miembros contra las posibles interferencias del centro, como ocurrió ya en 1787 con la Constitución de los Estados Unidos ${ }^{42}$; y debido a la llegada al poder de nuevas clases sociales, que con la eliminación del monopolio de la representación a la burguesía pretenden ponerse a salvo contra cualquier golpe de mayorías simples en un Parlamento que ya no es formado solo por una clase social ${ }^{43}$. La constitución pactada tiene que ser rígida, porque establece las reglas del juego, y estas no pueden ser cambiadas por mayorías electorales ${ }^{44}$.

Casi todos los Estados se han dotado de una constitución en sentido formal. Así, casi todos los Estados tienen constituciones rígidas. Sin embargo, la idea de constitución en sentido francés o norteamericano puede funcionar solo donde la base cultural que produjo las declaraciones de derechos es la misma. De no ser así, se crea una fractura. La gran división está centrada en la aceptación o el rechazo de las doctrinas del constitucionalismo, que desmiente la ecuación hecha por el art. 16 de la Declaración de $1789^{45}$ : la mayoría de los Estados del mundo se rigen por constituciones sin constitucionalismo ${ }^{46}$. En el mundo occidental se acepta la forma y el contenido; en

\footnotetext{
42 Es por este motivo, pues, que el proceso implica la participación de los Estados.

43 Pegoraro, L., Rinella, A. (2018). Derecho constitucional comparado, 2, Sistemas constitucionales, cit., tomo A, cap. II, p. 100 ss., p. 107 ss.

${ }_{44}$ Es cierto, sin embargo, que, incluso en ausencia de las condiciones mencionadas antes (necesidad de un pacto entre el centro y la periferia, o entre las clases sociales), en algunos casos, el deseo de consagrar la inmutabilidad de los principios ha llevado a los constituyentes a endurecer textos que se asumía fuesen dictados por la razón y por lo tanto lejos de cualquier posibilidad de cambio extemporáneo (constituciones revolucionarias francesas de 1791, 1793, 1795). Del mismo modo, hay que recordar que incluso una constitución reputada por muchos como flexible, como el Estatuto Albertino, se definía como irrevocable, así como se desprende de la fórmula de promulgación: «Por lo tanto, por Nuestra ciencia cierta, autoridad Regia, contando con el asesoramiento de Nuestro Consejo, hemos ordenado y ordenamos con fuerza de Estatuto y de Ley Fundamental, perpetua e irrevocable de la Monarquía, lo siguiente (...)».

45 Sobre las razones que empujan también los régimenes autocráticos a dotarse de una constitución v. Rinella, A. (2017). «Le costituzioni dei regimi autoritari», en Bagni, S., Figueroa Mejía, G., PAVAni, G. (eds), La ciencia del derecho constitucional comparado, cit., I, p. 1265 ss., y PEGORARO, L., Rinella, A. (2018). Derecho constitucional comparado, 2, Sistemas constitucionales, cit., tomo A, cap. II, p. 167 ss.

46 También hay casos de ordenamientos que hacen referencia al constitucionalismo, sin una constitución en sentido formal (la Unión Europea, el ordenamiento internacional). El Tratado de la
} 
otras regiones culturales a veces se acepta, debido a imposición, también el contenido, sin embargo no se implementa; muchas veces se acepta la forma pero se rechaza el contenido. Sin olvidar el efecto de retorno que, por lo menos, la aceptación formal de la idea de constitución determina en el ordenamiento, no solo en cuanto a los derechos y la forma de gobierno, sino también respeto a la misma cultura jurídica, cabe destacar, por lo tanto, la brecha entre el formante normativo (forma constitucional) y el marco jurídico-cultural que lo soporta ${ }^{47}$.

En su expansión, el constitucionalismo consigue adaptar su índole monoclase y «monoterritorial» a la llegada de nuevas clases sociales a la arena política, fundando la liberal-democracia, sin embargo no consigue aceptar el pluralismo cultural y proporcionar soluciones distintas a las que se basan en la división de poderes y el respeto a los derechos humanos. No sabe cómo conciliar respeto del hombre y respeto de las culturas, e impone la prevalencia del primero.

El constitucionalismo ha sido formalmente adoptado en todas partes o casi, pero limitadamente a la idea de que en la cúspide de la jerarquía de las fuentes se sitúa un texto llamado «constitución», casi siempre rígida.

Unión Europea, en su art. 6, se refiere a las «tradiciones constitucionales comunes de los Estados miembros» que «forman parte de la legislación de la Unión como principios generales»: cfr. PIzzorusso, A. (2002). Il patrimonio costituzionale europeo, Bologna, il Mulino. En relación con Europa, cfr. por ej. Dellavalle, S. (2002). Una costituzione senza popolo? La costituzione europea alla luce delle concezioni del popolo come «potere costituente», Milano, Giuffrè; Patruno, L. (2006). Il modello istituzionale europeo e l'idea di costituzione, Torino, Giappichelli; Figueruelo Burrieza, Á. (2006). Luces y sombras del Tratado Constitucional Europeo, Madrid, Dykinson; algunos libros colectivos: ToniatTi, R., Palermo, F. (eds) (2004). Il processo di costituzionalizzazione dell'Unione europea. Saggi su valori e prescrittività dell'integrazione costituzionale sovranazionale, Trento, Un. degli studi di Trento; ZaGReBeLSKY, G. (ed.) (2004). Diritti e Costituzione nell'Unione Europea, 2a ed., Roma-Bari, Laterza; RepeTto, G. (ed.) (2013). The Constitutional Relevance of the ECHR in Domestic and European Law, CambridgeAntwer-Portland, Intersentia; en la búsqueda de analogías y diferencias, orígenes, modelos, influencias mutuas y peculiaridades de las soluciones adoptadas, v. Palici Di Suni, E. (ed.) (2015). Diritto costituzionale dei paesi dell'Unione europea, 3a ed., Padova, Wolters Kluwer-Cedam. Del mismo modo, a los valores del constitucionalismo clásico (como los derechos humanos) hace referencia el Estatuto de las Naciones Unidas: la Declaración Universal de los Derechos Humanos adoptada el 10 de diciembre de 1948. Las referencias en el preámbulo a los «derechos humanos fundamentales» (en cuyo álveo se incluyen, no solo los derechos consagrados en la Declaración de 1789, sino también los derechos sociales y de participación), sin embargo, no encuentran sitio en la cultura jurídica de muchos Estados signatarios, lo que explica la falta de aplicación y las violaciones generalizadas y frecuentes de la Declaración en muchas partes del mundo.

47 A nivel doctrinario, los criterios comúnmente aceptados para clasificar las constituciones se basan sobre modelos hegemónicos, y sobre estos los profesores construyen tanto las clasificaciones históricas, como las sincrónicas, basadas en distintos elementos: legitimidad, flexibilidad o rigidez, incorporación o no de los derechos, etc. En particular, las clasificaciones tradicionales de las constituciones tienden a dar por sentada la fuerza expansiva del constitucionalismo [BLANCO VALDÉs, R.L. (2012). Voz «Constitucionalismo», cit., p. 40], tienden a resumir en una clase principal las constituciones que lo aceptan, poniendo al margen cuántas lo rechazan, tienden también a matizar las diferencias dentro de la primera clase, así como a basarse sobre una concepción estatal del Derecho. 


\subsection{El ataque al constitucionalismo: el neoconstitucionalismo}

Del constitucionalismo, las nuevas corrientes neoconstitucionalistas retoman la idea básica de la superioridad de los derechos humanos, rechazando sin embargo de hecho la superioridad de la constitución como ley fundamental decidida soberanamente por cada sociedad y el propio concepto de soberanía, además de la división de poderes, a favor de los Tribunales constitucionales, de los Tribunales internacionales, de la soft law producida fuera o al margen del circuito de legitimidad democrática.

Explica R. Viciano Pastor que "Como teoría del derecho, el neoconstitucionalismo —en particular a partir de los principios - aspira a describir los logros de la constitucionalización, entendida como el proceso que ha comportado una modificación de los grandes sistemas jurídicos contemporáneos. Por esta razón, está caracterizado por una constitución invasora, por la positivización de un catálogo de derechos, por la omnipresencia en la constitución de principios y reglas, y por algunas peculiaridades de la interpretación y de la aplicación de las normas constitucionales respecto a la interpretación y aplicación de la ley. Se trata, en definitiva, de recuperar en sentido fuerte la idea de constitución como norma jurídica suprema del Estado y fortalecer su presencia determinadora en el ordenamiento jurídico» ${ }^{48}$.

Con la expresión «neoconstitucionalismo» se pretende, en síntesis, indicar la evolución del pensamiento filosófico del constitucionalismo clásico, entendido como la orientación de la doctrina y las instituciones relativas a los límites jurídicos del poder, básicamente desde el periodo de la segunda postguerra mundial, hacia nuevos contenidos, identificados por algunos en: a) una constitucionalización de los derechos, entendidos como normas jurídicas, y por lo tanto directamente vinculantes tanto para los poderes públicos como, cuando es posible, en las relaciones entre particulares (y no como meros valores o normas programáticas); b) una judicialización de los derechos, como consecuencia de su alcance normativo; y c) una supranacionalidad de los derechos, como consecuencia de su «constitucionalización» en tratados internacionales regionales y universales ${ }^{49}$. M.

48 Viciano Pastor, R., Martínez Dalmau, R. (2011). «El nuevo constitucionalismo latinoamericano: fundamentos para una construcción doctrinal». Rev. gen. der. públ. comp., n. 9, p. 7. Ver Guastini, R. (2011). «A proposito di neo-costituzionalismo», Teoria pol., nueva serie, n. 1, p. 147 ss., con réplica de BArberis, M. (2011). «Esiste il neocostituzionalismo?». Analisi e dir., p. 3 ss.; SAStre Ariza, S. (1999). Ciencia jurídica positivista y neoconstitucionalismo, Madrid, McGraw Hill.

49 Cfr. Barberis, M. (2012). Stato costituzionale. Sul nuovo costituzionalismo, Modena, Mucchi, p. 18 ss., y Comanducci, P. (2009). «Formas de (neo)constitucionalismo: un análisis metateórico», en Carbonell, M. (ed.), Neoconstitucionalismo(s), 4a ed., Madrid, Unam-Trotta, p. 83. Prieto SANCHÍs, L. (2009). «Neoconstitucionalismo y ponderación judicial», ivi, p. 131, señala cinco aspectos esenciales del neoconstitucionalismo: «más principios que reglas; más ponderación que subsunción; omnipresencia de la Constitución en todas las áreas jurídicas y en todos los conflictos 
Barberis, por su parte, indica también otra característica importante de esta nueva visión: «una «conexión entre reglas jurídicas y valores morales a través de los principios constitucionales» ${ }^{50}$, que incide sobre el debate doctrinal y sobre las disputas jurisprudenciales, incluso «entre Tribunales», en torno a los criterios de interpretación constitucional» ${ }^{51}$.

Los efectos más vistosos de esta teoría son, sin embargo, de un lado, la no valoración de las teorías normativas de la constitución ${ }^{52}$ (mejor, la calificación como «normativa» de la constitución entendida como «conjunto de valores»); y por otro, una invasiva judicialización de la política y la concesión a los jueces de incontrolables funciones de decisión política. Esta corriente, alimentada por estudiosos de diferentes países ${ }^{53}$, puede ser utilizada para legitimar el «no Derecho» de la globalización, proporcionando el fundamento teórico para justificar el vacío de poderes de los Parlamentos, de la democracia directa y del propio poder de reforma constitucional; en definitiva, del mismo principio de soberanía popular ${ }^{54}$.

Por ej., P. Häberle, en la investigación sobre la «ciencia de la cultura», que es la base de su idea de constitución abierta, opta abiertamente por el modelo constitucional del «mundo libre», al que los estudiosos deberán dirigirse para mantener cualquier discurso «en la profundidad y en el discurrir de la historia» ${ }^{55}$. Su modelo interpretativo se basa en los derechos fundamentales, deduciendo a partir de ellos la superioridad de la constitución sobre el Estado, y del «Estado constitucional», incluso sobre el Estado de Derecho. Böckenförde acusa a esta teoría de llegar hasta una disolución completa de la constitución como norma, ya que con ella «la aper-

mínimamente relevantes, en lugar de espacios exentos en favor de la opción legislativa o reglamentaria; omnipotencia judicial en lugar de autonomía del legislador ordinario; y, por último, coexistencia de una constelación plural de valores, a veces tendencialmente contradictorios, en lugar de homogeneidad ideológica en torno a un puñado de principios coherentes entre sí y en torno, sobre todo, a las sucesivas opciones legislativas».

50 Barberis, M. (2012). Stato costituzionale. Sul nuovo costituzionalismo, cit., p. 52.

51 BAGNi, S. (2014). «Democratizzazione della giustizia costituzionale in America latina: uno sguardo da fuori». Riv. trim. dir. proc. civ., n. 4, p. 1387 ss., trad. esp. (2015). «Hitos de democratización de la justicia constitucional en América latina: una mirada desde afuera», en Tur Ausina, R. (ed.), Problemas actuales de Derecho constitucional en un contexto de crisis, Granada, Comares.

52 Del modo como fueron configuradas, entre los contemporáneos, por ej. por GARCía DE ENTERría, E. (1985, reimpr. 1988). La Constitución como norma y el Tribunal Constitucional, 3 a ed., Madrid, Civitas.

53 ... y muy evocada en América Latina, para contrarrestar el modelo de political law que caracteriza todavía el continente. Cfr. Sieder, R., Schjolden, L., Angell, A. (eds) (2005). The Judicialization of Politics in Latin America, New York, Palgrave Macmillan.

54 V. al respecto Shapiro, M., Stone Sweet, A. (2002). On Law, Politics, and Judicialization, Oxford, Oxford U.P.; Hirschl, R. (2004). Towards Juristocracy: The Origins and Consequences of the New Constitutionalism, Cambridge-London, Harvard U.P.

55 HÄBERLE, P. (1998). Verfassungslehre als Kulturwissenschaft, cit.; ID. (2000). «Métodos y principios de interpretación constitucional. Un catálogo de problemas». Rev. eur. dr. publ., n. 12 (3). 
tura se transforma incluso en «estructura» de la constitución», a la cual le sería propia «una permanente indeterminación y mutabilidad» ${ }^{56}$.

Los resultados se perciben de manera nítida en la destrucción de la jerarquía de fuentes, a favor de los «núcleos duros» de las constituciones — híper-constituciones metafísicas - individualizados con técnicas casuísticas por profesores y Tribunales constitucionales con total arbitrariedad, aprovechando el léxico a menudo vago o ambiguo de los textos: tanto en su actividad de delimitación de competencias de poderes y entes, como en la reconstrucción de las ponderaciones de principios, valores, derechos hechas por el poder constituyente y el legislativo.

Se percibe también en la individualización de límites al propio poder de reforma constitucional: con escasas excepciones, los Tribunales constitucionales, apoyados por parte de la doctrina académica, prohiben, a pesar de las supermayorías previstas en cada constitución para aprobar la reforma (e incluso del pueblo «soberano»), reformar lo que no les gusta a ellos ${ }^{57}$.

56 Böckenförde, E.-W. (1991). Staat, Verfassung, Demokratie, Studien zur Verfasssungstheorie und zum Verfassungsrecht, Suhrkamp, Frankfurt a.M., trad. it. (con otros estudios) en ID. (2006). Stato, costituzione, democrazia, Milano, Giuffrè, espec. p. 79 y p. 82. Adde los ensayos críticos de Martín De La Vega, A. (2017). «El concepto racional-normativo de Constitución», en BaGNI, S., Figueroa Mejía, G., Pavani, G. (eds), La ciencia del derecho constitucional comparado, cit., I, p. 1099 ss.; Navas Alvear, M. (2017). «El valor de una constitución en el marco del proceso político», ivi, I, p. 1131 ss. Sobre la interpretación en las diferentes teorías neoconstitucionalistas: Carbonell, M. (ed.) (2009). Neoconstitucionalismo(s), cit.; Dworkin, R. (1977). Taking Rights Seriously, Cambridge, Harvard U.P., cap. V, trad. esp. (1989). Los derechos en serio, 2a ed., Barcelona, Ariel, sobre el que véase Beltran, M. (1988). Originalismo e interpretación. Dworkin vs Bork: una polémica constitucional, Madrid, Civitas-Fac. de Derecho Un. Complutense; en clave crítica, Guastini, R. (2011). «A proposito di neo-costituzionalismo», cit.; v. también Sastre Ariza, S. (1999). Ciencia jurídica positivista y neoconstitucionalismo, cit. Continúa siendo de actualidad la famosa footnote four del caso United States vs Carolene Products Co., 304 US 144 (1938), por su carácter innovador del due process, de los derechos de las minorías y en general del rol de la Corte en la interpretación. Sobre este asunto entre otros muchos véase ACKERMAN, B. (1985). «Beyond Carolene Products». Harvard L.R., n. 98 (4), p. 713 ss.

57 Sobre este aspecto Ragone, S. (2011). I controlli giurisdizionali sulle revisioni costituzionali. Profili teorici e comparativi, Bologna, Bup, trad. esp. (2012). El control judicial de la reforma constitucional. Aspectos teóricos y comparativos, México, Porrúa; ID. (2013). «El control material de las reformas constitucionales en perspectiva comparada». Teoría y real. const., n. 31, p. 391 ss.; sobre la importancia del control (cada vez más frecuente) sobre la reforma constitucional cfr. Gözler, K. (2008). Judicial Review of Constitutional Amendments: A Comparative Study, Bursa (Turquía), Ekin; Góngora PIMENTEL, D. (2002). «El control de la reforma constitucional», en VEGA Gómez, J., Corzo Sosa, E. (eds), Tribunales y justicia constitucional. Memoria del VII Congreso Iberoamericano de Derecho Constitucional, México, Unam, p. 239 ss. (con particular referencia al contexto iberoamericano); AA.Vv. (2005). Reforma de la Constitución y control de constitucionalidad, Bogotá, Fac. Ciencias Jur. de la Pontificia Un. Javeriana; Ramírez Cleves, G.A. (2005). Límites de la reforma constitucional en Colombia: el concepto de Constitución como fundamento de la restricción, Bogotá, Un. Externado de Colombia; ZúÑIGA URBINA, F. (2006). «Control de constitucionalidad de la reforma constitucional». Est. const., n. 2, p. 429 ss.; García Belaunde, D. (2006). «Sobre el control de la reforma constitucional (con especial referencia a la experiencia jurídica peruana)». Rev. der. pol., n. 66, p. 477 ss.; Flores, I.B. (2007). «Sobre la (in) constitucionalidad de 'reformas constitucionales': a propósito de los casos de Chiapas, Michoacán y 
Se percibe además en el otorgamiento a los tratados internacionales (aprobados casi siempre por los Gobiernos o con la mayoría simple del Parlamento) de un rango superior a las propias constituciones o reformas constitucionales aprobadas por el poder constituyente o por amplias mayorías y/o el pueblo. La «bigher law» por lo tanto no es la ley aprobada por «we the people», sino la ley decidida por Gobiernos y Parlamentos, pese a lo que decía Hamilton en el ensayo número 78 del Federalist ${ }^{58}$. Dicho de otra manera, incluso donde la superioridad de los tratados está establecida en la constitución, ésta se convierte en flexible, confiando en las mayorías simples (o en los Gobiernos), a través de los tratados, para individualizar las reglas supremas ${ }^{59}$.

Se percibe finalmente en la atribución de sentidos universales (y de manera que se pretende vinculante) a palabras vagas como «dignidad», «democracia», «debido proceso», «derechos humanos», etc., interpretando de manera universal los conceptos de libertad individual y colectiva, respeto de las tradiciones, rol de la minoría, pluralismo y decisionismo, relaciones entre Derecho y ética, concentración y reparto del

Oaxaca». Cuest. const., n. 17, p. 259 ss.; Nogueira Alcalá, H. (2011 y 2012). «Poder constituyente y reforma constitucional: enfoque teórico y concreción práctica al caso chileno», en HäBERLE, P., García Belaunde, D. (eds.), El control del poder. Homenaje a Diego Valadés, 2 volúmenes, México, Unam, II, p. 459 ss., y Lima, Iidc-Un. Inca Garcilaso de la Vega-Iustitia, p. 1262 ss. Finalmente, muchos escritos recogidos ivi en el capítulo VII («Temas de reforma constitucional»), de F. Zúñiga Urbina, R.G. Ferreyra, H. Nogueira Alcalá, P. Salazar Ugarte, R. Hernández Valle, J.V. Haro García, R. Haro, y en el libro de Torres Estrada, P.R., Nuñez Torres, M.G. (eds) (2010), La reforma constitucional. Sus implicaciones jurídicas y políticas en el contexto comparado, México, Porrúa, y WoNG Meraz, V.A., León Bastos, C., Sosa Carrero, J.L. (eds.) (2017), La Reforma Constitucional y su Problemática en el Derecho Comparado, México, Lex.

58 «Si hubiera una antinomia irremediable entre la ley constitucional y la ley ordinaria, se deberá, naturalmente, dar preferencia a aquella que estamos ligados por obligaciones mayores o, en otros términos, se deberá preferir la constitución, a la voluntad de los representantes del pueblo la voluntad del pueblo mismo». Si los jueces de las leyes están habilitados a criticar en la forma y/o en el mismo contenido la revisión constitucional, como ocurre en muchos ordenamientos o por expresa disposición de la constitución o como consecuencia de las decisiones jurisprudenciales, evidentemente hay una deformación de la idea misma de control: desde el control sobre los abusos de la mayoría, en nombre de la supremacía constitucional, se convierte en el control del poder constituyente sobre el poder constituido, en todas sus manifestaciones. Se desplaza a otro lugar, entonces, la pregunta inicial puesta por Hamilton, por la filosofía política francesa y luego por Schmitt y por Kelsen: la pregunta hoy no es (solo) «¿quién controla la ley?»o «¿qué legitimación tienen los jueces para anular los actos del pueblo soberano, decididos por la mayoría de sus representantes?», sino más bien « ¿puede el mismo pueblo soberano, incluso con los procedimientos establecidos por el pacto constituyente, modificar el mismo?» y, en consecuencia, «¿quién es el custodio (no de la constitución sino) del núcleo de tal pacto?».

59 Aún más: se inaplica cuando el nivel de protección no es coherente con lo que establecieron los tribunales internacionales/supranacionales confiando en las mayorías simples (o en los Gobiernos), a través de los tratados, para individualizar las reglas supremas. No casualmente, la Constitución de EE.UU. prevée en su artículo II, sección II, § 2, que los tratados necesitan la aprobación de los 2/3 de los senadores. 
poder, control, descentralización, percepciones del ambiente y de la naturaleza, funcionalización del beneficio, dependencia de decisiones externas, posesión, etc. ${ }^{60}$

Cabe subrayar que estas teorías se pretende aplicarlas (y de hecho se aplican) no solo donde hay coherencia entre textos constitucionales y cultura jurídica liberal-democrática (que pone por encima de la jeraquía al ser humano, a la persona), sino también donde otros elementos históricamente estratificados condicionan pre-jurídicamente y vertebran el modo de concebir lo que en la cultura occidental se define «Derecho», como hemos dicho en el $\S 1$.

\section{LA INTEGRACIÓN DE CULTURAS AUTÓCTONAS EN EL CONSTITUCIONALISMO «FORMAL»Y EL RECHAZO DEL CONSTITUCIONALISMO}

A la «colonización» por parte, con anterioridad, del constitucionalismo, y ahora del neoconstitucionalismo, se oponen «culturas» con base en la tradición, la religión, y, de manera recesiva, en una visión de la sociedad distinta de la burguesa (el socialismo).

\subsection{La resistencia de la tradición}

El Derecho tradicional todavía impregna gran parte de la producción del mundo jurídico, aunque normalmente es desvaluado por los constitucionalistas ${ }^{61}$. La sensibilidad del Derecho privado comparado fue mayor respecto a los Derechos consuetudinarios, tribales, religiosos, y ciencias como la antropología permiten percibir lo que está detrás de las estructuras jurídicas «legales» ${ }^{62}$. No falta, sin embargo, también en

${ }^{60}$ Dworkin, R. (2002). «Taking Rights Seriously in Beijing». The N.Y. rev. of books, New York, p. 64 ss.; como testimonio acerca de que la fractura entre visiones distintas no es reconocida, Dworkin afirma, enfatizando las coordenadas del individualismo protestante/anglosajón (de posesión y de éxito), que, aunque existen diferencias entre los valores asiáticos y los valores occidentales, «a pesar de las grandes diferencias históricas y culturales, todos nosotros compartimos la misma situación humana fundamental. Nosotros tenemos una vida que llevar y una muerte que afrontar. Compartimos el mismo deseo de tener una justa parte de los recursos disponibles y una justa ocasión de realizar nuestra vida, antes que la de los otros».

${ }^{61}$ Sobre las tradiciones Legrand, P., Munday, R. (eds) (2003). Comparative Legal Studies, Cambridge, Cambridge U.P.; GLENN, H.P. (2014). Legal Traditions of the World: Sustainable Diversity in Law, 5 a ed., Oxford, Oxford U.P., trad. it. de la 2a ed. (2011). Tradizioni giuridiche nel mondo. La sostenibilità della differenza, Bologna, il Mulino; BennetT, T.W. (2006). «Comparative Law and African Customary Law», en Reimann, M., Zimmermann, R. (eds), The Oxford Handbook of Comparative Law, cit., p. 641 ss.

62 Bennet, T.W. (2006). «Comparative Law and African Customary Law», cit., p. 641 ss., y espec. p. 671 s.; Somma, A. (2012). «Le parole della modernizzazione latinoamericana. Centro, periferia, individuo e ordine». Research paper series, Frankfurt a.M., Max-Planck-Institut für Europäische Rechtsgeschichte — Max Planck Institute for European Legal History, n. 5, p. 1 ss.; ID. (2012). «Tradizione 
el Derecho público, quien trata de conciliar el Derecho consuetudinario (tradicional) y el Derecho constitucional. Parece posible - por usar las categorías de M. Carducci - un «Derecho constitucional altruista», anclado en las tradiciones y en las costumbres (aunque no solo) ${ }^{63}$.

«La tradición es una obra de la representación de la realidad basada en un conjunto de datos previamente aprendido» ${ }^{64} \mathrm{y}$ el Derecho tradicional/consuetudinario es la base de un «esquema teórico [que] permite evaluar las reformas partiendo de los conceptos de tradición y pluralismo jurídico. El Derecho cosmopolita subalterno u de los oprimidos es un proyecto cultural, político y social que incluye un elemento jurídico». Por lo tanto, se basa en la categoría de «tradiciones jurídicas no hegemónicas para evaluar si es posible su uso en las luchas contra el neoliberalismo» ${ }^{65}$.

Las experiencias de constitucionalización de las tradiciones que se toman como referencia son «las constituciones del buen vivir, en especial la ecuatoriana; la Constitución de Sudáfrica, integrada por el Tribunal Constitucional que ha reconocido, entre los valores y principios del nuevo ordenamiento democrático, el tradicional de ubuntu; y, finalmente, la nueva Constitución de Bután que introdujo en la Carta fundamental el concepto de Gross National Happiness». Estos valores se han introducido «a través de las cláusulas constitucionales (Ecuador y Bután) o criterios de interpretación de la Constitución (Sudáfrica) que remiten a visiones del mundo de la tradición cultural indígena, con el fin de facilitar, por todos los sectores de la sociedad, la identificación personal en el contexto constitucional. De esta manera, la propia Constitución se propone como una ruptura con el pasado y la piedra angular para la cons-

giuridica occidentale e modernizzazione latinoamericana. Petrolio, democrazia e capitalismo nell'esperienza venezuelana», en AA.Vv., Zeitschrift des Max-Planck-Instituts für europäische Rechtsgeschichte, n. 20, p. 190 ss. V. también en Losano, M.G. (2000). I grandi sistemi giuridici, cit., p. 257 ss., el capítulo sobre «La consuetudine e il diritto».

${ }^{63}$ Carducci, M. (2003). Por um Direito Constitucional Altruísta, Porto Alegre, Livraria do advogado. Sobre todo v. hoy del mismo Autor (2017). «'Ragione politica' della comparazione e 'costituzionalizzazione' delle tassonomie», cit.

${ }^{64}$ GLenn, H.P. (2014). Legal Traditions of the World, cit., p. 5 ss.

65 Santos, B. DE Sousa (2009). Una epistemología del Sur. La reinvención del conocimiento y la emancipación social, México, Siglo XXI; además CARDUCCI, M. (2010). «Coinvolgimento e distacco nella comparazione mondo». Bol. mex. der. comp., n. 128, p. 595 ss.; ID. (2012). «Epistemologia del Sud e costituzionalismo dell'alterità». Dir. pubbl. comp. eur., n. 2, p. 319 ss.; BALDIN, S. (2015). «The Concept of Harmony in the Andean Transformative Constitutionalism: A Subversive Narrative and its Interpretations», en ID. (ed.), «Narraciones contrahegemónicas y derecho», secc. monográfica de la Rev. gen. der. públ. comp., n. 17, p. 1 ss.; ToniatTi, R. (2017). «Il paradigma costituzionale dell'inclusione della diversità culturale in Europa e in America Latina: premesse per una ricerca comparata sui rispettivi modelli», en Bagni, S., Figueroa Mejía, G., Pavani, G. (eds), La ciencia del derecho constitucional comparado, cit., III, p. 1445 ss.; ID. (2016). «La razionalizzazione del 'pluralismo giuridico debole': le prospettive di un nuovo modello giuridico e costituzionale nell'esperienza africana», en AA.Vv., Le trasformazioni costituzionali del secondo millennio, Rimini, Maggioli, p. 449 ss.; Colomer Viadel, A. (2015). «Una teoría constitucional de la supervivencia para América Latina». Rev. per. der. públ., n. 31, p. 175 ss. 
trucción de un futuro realmente compartido» ${ }^{66}$. Incluso la reciente Constitución de Madagascar de 2010, aprobada tras una compleja transición democrática, constitucionaliza las tradiciones de ese pueblo. El preámbulo hace referencia, por ejemplo, a la creencia en Dios, Supremo Creador (Andriamanitra Andriananabary), la protección de la biodiversidad, las estructuras de gobierno tradicionales locales, la promoción de una sociedad que pueda vivir en armonía y en el respeto del otro, y sepa revalorizar «la richesse et (...) dynamisme de ses valeurs culturelles et spirituelles à travers le «fanaby maha-olona» (principio de existencia)», encontrando «son originalité, son authenticité et sa malgachéité (...) en conservant ses valeurs et principes fondamentaux traditionnels basés sur le fanaby malagasy qui comprend «ny fitiavana, ny fihavanana, ny fifanajàna, ny fitandroana, ny aina», et privilégiant un cadre de vie permettant un «vivre ensemble» sans distinction de région, d'origine, d'ethnie, de religion, d'opinion politique, ni de sexe». Finalmente, las estructuras comunitarias básicas — las sedes decisorias (Fokonolona) organizadas en aldeas (Fokontany) — constituyen «un marco de vida, de emancipación, de intercambio y de concertación de los ciudadanos».

Dentro de las tradiciones, el Derecho consuetudinario es una base importante cuando no exclusiva. (También concurren, de hecho, el Derecho religioso, el animismo, así como otros tipos de reglas.) La noción de costumbre viene frecuentemente referida a los ordenamientos jurídicos de la sociedad «primitiva» (mejor, ctónica), bien se remonten los mismos a la antigüedad, bien estén todavía vivos y sean jurídicamente no evolucionados. En tales situaciones la costumbre asume un significado extenso, dirigido a comprender fenómenos jurídicos que mejor serían encuadrados en el Derecho de derivación divina, por las motivaciones conexas a la influencia de entidades sobrenaturales ${ }^{67}$. En general, sin embargo, prevalece en aquella sociedad la idea de que los comportamientos establecidos por los antepasados, o por los ancianos, son obligatorios y no susceptibles de modificación. Por otro lado, diversos textos que han constituido las bases de referencia del Derecho moderno han sido el resultado de un proceso de codificación o compilación de costumbres preexistentes ${ }^{68}$ (desde el Corán

66 BAgNi, S. (2013 y 2014). «Dal Welfare State al Caring State?», en ID. (ed.), Dallo Stato del bienestar allo Stato del buen vivir? Innovazione e tradizione nel costituzionalismo latino-americano, Bologna, Filodiritto, y Ann. italo-iberoam. dir. cost., Napoli, Esi; ID. (2014). «Il sumak kawsay»: da cosmovisione indigena a principio costituzionale in Ecuador», en BALDIN, S., ZAGO, M. (eds.), Le sfide della sostenibilità. Il buen vivir andino dalla prospettiva europea, Filodiritto, Bologna, p. 62 ss. Sobre los procesos de constitucionalización v. también BoyD, D.R. (2012). The Environmental Rights Revolution: A Global Study of Constitutions, Human Rights, and the Environment, Vancouver, UBC Press. Para algunas aplicaciones particulares de la filosofía del buen vivir véase Bonilla MaLdonado, D. (ed.) (2010). Justicia colectiva, medio ambiente y democracia participativa, Bogotá, Un. de los Andes; sobre presupuestos y la finalidad, vid. Ávila PaCHeco, V.M., Peña Meléndez, W.L. (eds.) (2011). Descolonización del Estado en América Latina, Bogotá, Un. Libre.

${ }^{67}$ Bennett, T.W. (2006). «Comparative Law and African Customary Law», cit., p. 641 ss.

68 Sobre las costumbres BobBio, N. (1942, reimpr. 2010). La consuetudine come fatto normativo, Padova, Cedam, y Torino, Giappichelli; Zagrebelsky, G. (1970). Sulla consuetudine costituzionale nella teoria delle fonti del diritto, Torino, Utet. 
a la Biblia y a los Veda — libros sagrados primitivos de la India-); codificaciones y compilaciones que también en épocas recientes han marcado la evolución de determinados ordenamientos ${ }^{69}$.

A través del reconocimiento de la tradición toman relieve jurídico formas de producción vinculadas no solo a las costumbres, sino también a las creencias ultraterrenales, o paradójicamente a lo que más se considera terrenal: la Madre Tierra. Cabe señalar, en este sentido, la incorporación en algunos textos constitucionales andinos de referencias a la Pachamama, que, en la Constitución de Ecuador, se configura como un sujeto de Derecho ${ }^{70}$. Mientras que el art. 4 de la Constitución boliviana establece el respeto y la garantía de la libertad de religión y de las creencias espirituales, de acuerdo con sus visiones del mundo. Del mismo modo, hay que recordar otra vez la incorporación del ubuntu —el conjunto de las tradiciones espirituales africanas - en el Derecho constitucional de Sudáfrica (por parte de la Corte Constitucional) y otros países de África del Sur ${ }^{71}$, además del reconocimiento — también a nivel constitucional— del Derecho tradicional en otros ordenamientos, como por ej. India.

69 La doctrina comparadística [DAvid, R., Jauffret-Spinosi, C. (2002). Les grands systèmes de droit contemporains, 11 a ed., Paris, Dalloz, trad. it. (2004). I grandi sistemi giuridici contemporanei, 5 a ed. coord. por SACCO, R., Padova, Cedam, trad. esp. (2010). Los grandes sistemas jurídicos contemporáneos, México, Unam (ed. actualizada DAvid, R. JAuffret-Spinosi, C., Goré, M. (2016). Les grands systèmes de droit contemporains, 12a ed., Paris, Dalloz)] pone de relieve por ej. que Madagascar y toda el África subsahariana han vivido durante siglos, y aún lo siguen haciendo, de acuerdo con usos (patriarcales y matriarcales) a los que se ha superpuesto el Derecho colonial. El propio common law inglés se ha formado sobre la base de un Derecho consuetudinario preexistente [MATTEI, U. (2014). Il modello di common law, 4a ed., Torino, Giappichelli; Criscuoli, G., Serio, M. (2016). Nuova introduzione allo studio del diritto inglese. Le fonti, 4a ed., Milano, Giuffrè]; así como a partir de 1453 asumió en Francia una particular relevancia la recopilación y la progresiva consolidación de las coutumes. A pesar de que no pueden ser consideradas como una verdadera fuente del Derecho, las costumbres «han sido empleadas en varias ocasiones para adaptar el derecho islámico a las tradiciones y a las exigencias de comunidades muy diferentes entre sí. En muchos casos, pues, ha permitido la progresiva introducción en algunos países islámicos de elementos típicos del derecho de países extranjeros. Tampoco han faltado casos en los que la costumbre ha prevalecido sustancialmente sobre la shart' $a$, aun cuando desde una perspectiva puramente teórica no son admitidas costumbres praeter o contra legem»: Oliviero, M. (2012). Voz «Derecho islámico», cit., p. $123 \mathrm{~s}$.

${ }^{70}$ Art. 71 ss. Para la relación entre Derecho y tierra en Brasil v. Martini Vial, S.R. (2003). Propriedade da Tierra, Porto Alegre, Livraria do Advogado, trad. it. (2006). La "costituzione della terra» in Brasile, Cavallino, Pensa.

71 Ver supra, $\$ 2$. Se añade que las visiones integradoras de las personas y de los grupos con la naturaleza son lejanas a las occidentales, aunque éstas en las últimas décadas han manifestado, en el debate científico, en la legislación, y en la jurisprudencia, una marcada intención de conciliar derechos de los particulares y de los grupos, de una parte, y ambiente, por el otro. De la vasta producción v. por ej. YARZA, F.S. (2012). Medio ambiente y derechos fundamentales, Madrid, CEPC; Cordini, G., FoIs, P., Marchisio, S. (2017). Diritto ambientale. Profili internazionali europei e comparati, 3a ed., Giappichelli, Torino; Crosetti, A., Ferrara, R., Fracchia, F., Olivetti Rason, N. (2008). Diritto dell'ambiente, 2a ed., Roma-Bari, Laterza. 
«Desde los albores de la humanidad — afirma A. Acosta - el miedo a los impredecibles elementos de la Naturaleza estuvo presente en la vida de los seres humanos. Poco a poco la ancestral y difícil lucha por sobrevivir se fue transformando en un desesperado esfuerzo por dominar la Naturaleza. Paulatinamente el ser humano, con sus formas de organización social antropocéntricas, se puso figurativamente hablando por fuera de la Naturaleza. Se llegó a definir la Naturaleza sin considerar a la humanidad como parte integral de la misma. Y con esto quedó expedita la vía para dominarla y manipolarla» ${ }^{72}$.

«En los orígenes, —explica Silvia Bagni ${ }^{73}$ — la Naturaleza era el único término de comparación para el hombre, que inspiraba miedo y al mismo tiempo era adorada como divina». Las constituciones andinas — continúa- «positivizan algunos principios clave de una tradición típicamente oral insertándolos en un documento escrito. «El carácter más evidente de la tradición jurídica ctonia está representado por su naturaleza oral» ${ }^{74}$. Podría ser una forma para incluir esta tradición en la de de civil law, apagándola, pero a la vez es una forma de renovarlas e integrar a ambas, pues estos principios se vuelven parámetros en el control de constitucionalidad, no meras normas programáticas, de principio o aparentemente proclamatorias como los preámbulos, y entonces incluso las instituciones típicas de nuestra tradición tendrán que hacer las cuentas con ellos.

Siendo tradiciones interdependientes ${ }^{75}$ (ninguna vive separada de las demás), incluso las jurídicas indígenas coexisten desde hace ya mucho tiempo con las demás, las cuales, religiosas y no religiosas, han adoptado las estructuras y las instituciones propias del Estado nacional y el Derecho positivo. El resultado hasta ahora ha sido que el Derecho autóctono ha sido aniquilado por el de origen occidental, o como mucho considerado como una reserva. Aunque Glenn afirme que ha habido una implícita y explícita oposición a escribir el Derecho ctónico, sobre todo por razones sustanciales conectadas a la voluntad de que quedase un Derecho sin casta de intérpretes $^{76}$, la mezcla que se ha producido en algunos ordenamientos estatales como el de Ecuador o Bolivia abre un flujo de ellos hacia nosotros, y ya no solo lo contrario. La constitucionalización del principio no afecta a la oralidad de la tradición indígena, sino que impone a los jueces y a los operadores jurídicos de civil law actualizarse respecto a la tradición local, entendiendo los cambios cada vez que la cláusula constitucional debe de ser interpretada y aplicada. Ello los obliga a entrar en contacto con una lógica diversa de aquella a la que están acostumbrados, ya no binaria, aristotélica,

72 Acosta, A. (2008). «La Naturaleza con Derechos. Una propuesta de cambio civilizatorio». http://www.lai.at/attachments/article/89/AcostaNaturaleza\%20Derechos\%202011, p. 2.

73 BAGNi, S. (2013). «L'armonia tra il sé, l’altro e il cosmo come norma: la costituzionalizzazione della cultura tradizionale nei Paesi andini e in prospettiva comparata». Governare la paura, Special Issue, p. 220 ss.

${ }^{74}$ GLENN, H.P. (2011). Tradizioni giuridiche nel mondo, cit., p. 120.

75 Ibidem, p. 579.

76 Ibidem, p. $121 \mathrm{~s}$. 
sistemática, sino múltiple, inclusiva y comunitaria, abriendo paso a la "diversidad sostenible" ".

Acerca del ubuntu, — recuerda M. Nicolini ${ }^{77}$ — «la Corte constitucional sudafricana enfatiza el elemento solidario y communitarian intrínseco al concepto de $u b u n t u^{78}$, que suaviza los institutos del Derecho romano-holandés, rígidamente basados en conceptos como «freedom and sanctity of contract ... rooted in the political and economic philosophies of laissez-faire liberalism and individualism ${ }^{79}$, dejando a un lado «the typical Western conception of society as a collection of atomistic individuals ${ }^{80}$. El ubuntu define un concepto africano de fraternidad que transforma al tríptico liberal de instrumento a finalidad de la postcolonial public policy en las áreas geo-jurídicas africanas. Permite, además, elaborar una nueva tradición jurídica donde el postcolonial discourse incorpora principios, valores, conceptos del Derecho tradicional según narraciones que seguramente tienen un estilo à l'européene, pero promueven el desarrollo de la experiencia jurídica comunitaria africana según directrices autónomas de las eurocéntricas y coloniales». Por otra parte, el Derecho tradicional ha sido objeto de codificación (restatement $)^{81}$. Ello — subraya este autor ${ }^{82}$ — «contrasta con el pluralismo africano y la realidad social y jurídica porque origina un nuevo Derecho tradicional homogéneo y «racionalizado» ${ }^{83}$, en el cual dejan de ser aplicados institutos que, conforme a sus repugnancy clauses, son «contrary to justice and humanity» —es decir, al espíritu del Derecho occidental, europeo y colonial ${ }^{84}{ }$.

Los sistemas africanos, debido a su cercanía con el Derecho tradicional, sufren así la supremacía — jurídica, histórica y social— de los sistemas occidentales europeos. «Esta es la razón de la inclusión irregular del African law entre las familias jurídicas: el Derecho africano impone adoptar una concepción no juspositivista; y los problemas

77 Nicolini, M. (2018). «Disengaging Africa from the colonial syndrome: per una sistemologia oltre Finisterrae». Dir. pubbl. comp. eur., n. 2, $\$ 7$.

78 Por ej. S v. Makwanyane and Another (CCT3/94) [1995] ZACC 3; 1995 (6) BCLR 665; 1995 (3) SA 391; [1996] 2 CHRLD 164; 1995 (2) SACR 1 (June 6, 1995).

79 Hutchinson, D., Pretorius, CH.-J. (eds) (2012). The Law of Contract in South Africa, Cape Town, Oxford U.P., p. 23; Bhana, D., Pieterse, M. (2005). «Towards a Reconciliation of Contract Law and Constitutional Values». The South African L.J., p. 866 ss.

${ }^{80}$ Constitutional Court sudafricana, Port Elizabeth Municipality v. Various Occupiers: (CCT 53/03) [2004] ZACC 7; 2005 (1) SA 217 (CC); 2004 (12) BCLR 1268 (CC) (1 October 2004), § 37.

81 Prinsloo, M.W. (1987). «Restatement of Indigenous Law», Comp. int. L. Journ. Southern Africa, p. 411. Para las colonias francesas v. Berinzon, M., Briggs, R.C. (2016). «Legal Families Without the Law: The Fading of Colonial Law in French West Africa». Am. journ. comp. law, n. 64, p. 341.

${ }^{82}$ Nicolini, M. (2018). «Disengaging Africa from the colonial syndrome», cit., $\$ 3$.

83 Woodman, G.R. (2011). "A Survey of Customary Laws in Africa in Search of Lessons for the Future», en Fenrich, J., Galizzi, P., Higgins, T.E. (eds), The Future of African Customary Law, Cambridge, Cambridge U.P., p. 12.

${ }^{84}$ Chanock, M. (2001). The Making of a Legal Culture, 1902-1936: Fear, Favour and Prejudice, Cambridge, Cambridge U.P., p. 282. En los territorios franceses, un decreto del 10 de noviembre de 1903 impidió la aplicación del Derecho tradicional si iba en contra de los «principes de la civilisation française»: Berinzon, M., Briggs, R.C. (2016).«Legal Families Without the Law», cit., p. 342. 
crecen porque este Derecho encuentra, en los distintos ordenamientos constitucionales, sistemas de distinto origen: el Derecho-romano holandés, el common law, el Derecho religioso». Si además — concluye Nicolini ${ }^{85}$ — «se lee la retórica de la misión civilizadora europea por los pueblos de África ${ }^{86}$ a la luz del «tríptico colonial» (política de potencia, hegemonía comercial, control geopolítico), en consecuencia la extensión a África de los principios del constitucionalismo liberal no es finalidad de la política colonial, sino instrumento para su cumplimiento. No es ajena ni la «política religiosa» de los Estados europeos, dado que el cristianismo «encarna la religión que corresponde a esta civilización superior» ${ }^{87}$; ni la «transformation of racial difference into moral and even metaphysical difference»: ambas «aimed at the justification of European colonization» ${ }^{88}{ }$.

Como subraya R. Sacco acerca del Derecho africano - pero ello es cierto incluso para el oriental o indígena- «La regla tradicional africana no es escrita. Muchos autores han enfatizado este carácter, la oralidad. (...) El proceso y la sentencia no se basan en escritos. La doctrina — si la hay- es un saber jurídico transmitido oralmente» ${ }^{89}$. Precisa que «Las reglas tradicionales en cuestión pertenecen por definición a comunidades sin un lenguaje jurídico sofisticado», y que en los sistemas tradicionales «el efecto se conecta a eventos que el espíritu europeo puede considerar como elementos del «tipo», pero también a otros que un europeo, cuanto más sea «jurista», menos consideraría jurídicamente relevantes». «La razón que fundamenta una decisión jurídica (judicial o individual incluso) se expresa como mucho con un proverbio alusivo» ${ }^{90}$.

\subsection{El Derecho de derivación divina y divino}

También el Derecho de derivación divina concurre a enfatizar la escisión entre constitucionalismo y distintas culturas jurídicas. Es suficiente considerar los casos del Derecho hindú, chino, japonés y sobre todo islámico.

85 Nicolini, M. (2018). «Disengaging Africa from the colonial syndrome», cit, $\S 5$.

86 Creus, J. (1994). «Guinea Equatorial, 1883-1911: la invenció d'una identitat». Recerques: bistòria, economia, cultura, n. 30, p. 104

${ }^{87}$ Diala, I. (2000). «Biblical Mythology in André Brink's Anti-Apartheid Crusade». Research in African Literatures, n. 31, p. 80.

88 Mann, K., Roberts, R. (1991). Law in Colonial Africa, Portsmouth-London, Heinemann Educational Books, n. 20, p. 3.

89 Sacco, R., con la colaboración de Guadagni M., Aluffi Beck-Peccoz R., Castellani, L. (2006). Il diritto africano, en SACco, R. (ed.), Trattato di diritto comparato, Torino, Utet, p. 71. Véase también ID. (2000). «Lingua e diritto». Ars interpretandi, n. 5, p. 117 ss.

90 SACco, R. (2006). Il diritto africano, cit., p. 72. Para un análisis de un caso famoso -el proceso al leader keniata Y. Keniatta, donde se cruzan tradiciones, oralidad, lenguaje, igualdad, valores occidentales - v. Lanzoni, L. (2015). «The Trial of Yomo Keniatta, by Montagu Slater: Oral Tradition and Fundamental Rights in the Trial», en WARD, I. (ed.), Literature and Human Rights. The Law, the Language and the Limitations of Human Rights Discourse, Berlin, de Gruyter, y en general BENNETT, T.W . (2006). «Comparative Law and African Customary Law», cit. 


\subsubsection{Derecho hindú}

Sobre las características básicas del Derecho hindú, hay que subrayar que no se trata de un Derecho divino (es decir, puramente religioso), sino de un Derecho de «inspiración» religiosa. «De hecho, las normas jurídicas aun siendo reconducibles a concepciones filosófico-religiosas típicas del pensamiento hinduista (en particular a la ley de base del deber ser, el dharma) no constituyen una aplicación directa de preceptos religiosos y no encuentran su origen en un conjunto de fuentes escritas destinadas a tal efecto. Los primeros textos de referencia, los Veda, son un conjunto de himnos y cantos religiosos en versos, carentes de fines preceptivos, salvo lo que concierne a indicaciones sobre rituales y ceremonias sagradas. Por otra parte, el verdadero derecho hindú se elabora a través de comentarios o interpretaciones de los Veda $(\ldots){ }^{91}$.

Como bien destaca D. Amirante ${ }^{92}$, «La del «Derecho hindú» es una de las «tradiciones jurídicas» (...) más antiguas del mundo. Algunas reconstrucciones históricas señalan como origen de los primeros textos de referencia (las escrituras sagradas de los Veda) hasta 1500 a.C. Se trata sin embargo de una experiencia jurídica que nunca ha cristalizado plenamente como «sistema» de reglas uniformemente aplicables, sea por sus características intrínsecas, o bien por la extremada amplitud de los territorios en los cuales ha sido aplicada, sea por la notable complejidad de la estructura social de los pueblos que la han utilizado».

Como señala Lingat, por tanto «existen dos características fundamentales que permiten diferenciar notablemente el Derecho hindú de aquel de matriz occidental o del mismo Derecho islámico». Por un lado, debe subrayarse «la falta de verdaderas fuentes escritas (...) en cuanto ni la ley, en el sentido de acto legislativo, ni las decisiones jurisdiccionales contribuyen a su formación». Por el otro, cabe destacar que «los hindúes no han elaborado el Derecho a partir del elemento que en occidente ha bastado para hacerlo el objeto de una disciplina específica, a saber, el elemento coercitivo (...) Ellos se han acogido a un concepto más general que supera con mucho el ámbito del Derecho sin siquiera abarcarlo enteramente, el deber (o dharma)» ${ }^{93}$. Concluye Amirante que «Al principio del segundo milennio, tras más de cincuenta años de vigencia de la constitución india (...), la relación entre la tradición jurídica hindú y el Derecho positivo de la República independiente todavía se puede describir como una relación entre "un Derecho suprimido, pero que el pueblo sigue todavía, y un nuevo Derecho que intenta arraigar el primero con la fuerza del mandato popular: (...) una situación de gran dinamismo en la que la tendencia a largo plazo es favorable a la afirmación del Derecho nuevo (Annoussamy)"».

91 Véase la bibliografía citada en la nota 24.

92 Amirante, D. (2012). Voz «Derecho hindú y derecho indio», cit., p. 116 ss.

93 De Lingat, $R$. véase véase la bibliografía citada en la nota 24. 


\subsubsection{Derecho chino}

En China, nos recuerda M. Timoteo ${ }^{94}$, «las instancias primarias para la gestión de las relaciones jurídicas se afirman dentro de los núcleos sociales de base en los cuales se localizan los individuos. Estos núcleos (familia, clan, corporaciones, aldeas) son importantes sobre una escala de valores, de origen confuciana, que exalta la dimensión comunitaria y solidaria. Emblemática, para este propósito, resulta la posición respecto de las controversias: en caso de una ruptura del orden social, éstas, si son funestamente insurrectas, en primer lugar se enfrentan dentro de los circuitos sociales a través de procedimientos extrajudiciales, de amigable composición, siendo tales procedimientos más adecuados para el restablecimiento de la armonía social» ${ }^{95}$.

De tales premisas, los confucianos distinguen netamente dos dimensiones fundamentales del Derecho: el $f a$, es decir, el Derecho escrito, expresión autoritaria del poder centralizado; y el $l i$, es decir, la regla ritual, convencional, arraigada a nivel social, que manifiesta un espíritu de adhesión a un modelo de orden social y universal.

Aun en un marco de notables transformaciones a lo largo de los siglos, con las últimas reformas constitucionales y del Derecho privado y mercantil — concluye Timoteo- «los observadores lamentan un bajo nivel de operatividad de las nuevas normas, y una patológica calidad refractaria del sistema jurídico chino para ajustarse a los estándares occidentales. Por otro lado, parece poco verosímil una praxis de sumisa imitación de los modelos externos por parte de China, ya que este país se encuentra dotado también en el ámbito jurídico de una memoria histórica propia de prolongado tiempo, la cual inevitablemente introduce en el proceso de modernización, reacciones de sustrato manifiesto o latente».

\subsubsection{Derecho japonés}

«El sistema jurídico japonés a veces es presentado como el ejemplo de una importación exitosa de modelos europeos en el contexto de Asia Oriental; a veces como el baluarte de la tradición jurídica confuciana y en consecuencia como país donde el impacto del modelo cultural confuciano es todavía dominante. En la mayoría de los casos, sin embargo, prevalece una original combinación de las dos ideas anteriores, y

94 Timoteo, M. (2012). Voz «Derecho chino», en Pegoraro, L. (ed.), Glosario de Derecho público comparado, cit., p. 92 ss.; ver también CAVALIERI, R. (1999). La legge e il rito. Lineamenti di storia del diritto cinese, cit.

95 Todavía, particularmente en las zonas rurales, «persiste un sistema de gestión de las controversias basado en las instancias de los poderes periféricos que, no muy distante de lo que sucedía en el legal process a finales del Imperio, se colocan dentro de un diseño tácito de distribución de las competencias con el poder central». Sobre formas alternativas de resolución judicial cfr., también para la bibliografia, Pavani, G. (2018). «El poder judicial», cap. IX, secc. V, de Pegoraro, L., Rinella, A. Derecho constitucional comparado, 2, Sistemas constitucionales, cit., tomo B, espec. $§ 6.2$ ss. 
del sistema jurídico japonés se da una representación — tan sagazmente definida por Andrea Ortolani ${ }^{96}$ — “esquizofrénica” ${ }^{97}$.

Durante mucho tiempo aislado del mundo occidental, también Japón inserta un constitucionalismo moderno en un complejo sistema de Derecho tradicional, de alguna manera cercano al Derecho chino, pues desde el siglo V, junto con la escritura china, se importaron también la filosofía confuciana y la religión budista, y con ellas los principios jurídicos como en particular la estructura jerárquica de la sociedad, y la preferencia por las fuentes tradicionales y los procedimientos de conciliación ${ }^{98}$. El proceso de centralización, focalizado en la figura del Emperador, al que se atribuye origen y naturaleza divinas, se realiza en el siglo viI, también por un proceso de consolidación del las reglas penales y administrativas, aplicadas por los funcionarios del Tennō, pero con dificultades por la resistencia de las costumbres locales y otras reglas ${ }^{99}$.

El proceso de ocidentalización se hizo más evidente con la adopción de la constitución impuesta por los Estados Unidos y las reformas en campo económico ${ }^{100}$, del Derecho mercantil, de sociedades y quiebras (con influjos estadounidenses). Permanece sin embargo la adversión hacia el litigio y la tendencia a usar métodos alternativos de risolución informal de los conflictos, como conciliación y arbitraje. «La natural consecuencia de ello ha sido, incluso en época contemporánea, el escaso recurso a los tribunales y al sistema judicial tradicional, menos los casos en los que los demás mecanismos sean ineficaces ${ }^{101}$. Otra consecuencia es la distinta percepción de los derechos, siendo los conceptos occidentales como «derecho subjetivo», «fundamental», «humano», etc., ajenos a la cultura japonesa ${ }^{102}$.

${ }^{6}$ Ortolani, A. (2009). «Il giri e la questione della mentalità giuridica giapponese». Riv. dir. civ., n. 3, p. 371 ss.

97 Así Colombo, G.F. (2013). «Japan as a Victim of Comparative Law». Mich. st. int. law rev., n. 22, p. 731 ss., con síntesis en (2017). Riv. diritti comp., n. 2, p. 1.

98 Colombo, G.F. (2008). «Giappone», en Cavalieri, R. (ed.), Diritto dell'Asia Orientale, Venezia, Cafoscarina, p. 73 ss.; SAsso, F., Lo Coco, D. (2016). Giappone: un diritto originale alla prova della globalizzazione, Palermo, Un. di Palermo, p. 19; Ajani, G., Serafino, A., Timoteo, M. (2007). Diritto dell'Asia orientale, Torino, Utet, p. 477 ss. En la literatura italiana, algunos ensayos sobre Japón se encuentran en Groppi, T., Piergigli, V., Rinella, A. (eds) (2008), Asian Constitutionalism in Transition, Milano, Giuffrè; v. también, en Losano, M.G. (2000). I grandi sistemi giuridici, cit., el cap. sobre «I diritti dell'Asia orientale», p. 411 ss. Esencial es Haley, J.O. (1998). The Spirit of Japanese Law, Athens, Un. of Georgia, y útil Milhaupt, C.J., Ramseyer, J.M., West, M. (eds) (2006). Japanese Legal System, Stanford, Foundation.

99 Cfr. Colombo, G.F. (2008). «Giappone», cit., p. 77.

${ }_{100}$ V., aunque antiguo, Losano, M. (1984). Il diritto economico giapponese, 2a ed. ampliada con una apéndice sobre Derecho coreano, Milano, Unicopli.

101 Sasso, F., Lo Coco, D. (2016). Giappone, cit., p. 43, y sobre todo Haley, J.O. (1995). «The Myth of the Reluctant Litigant», en YANAGIDA, Y., ET AL. (eds) (1995 y1978), Law and Investments in Japan, Cambridge-London, Harvard U.P., p. 475 ss., y Journ. of jap. stud., n. 4, 359 ss. Cfr. también Port, K.L. (ed.) (1996). Comparative Law and the Legal Process in Japan, Durham, Carolina Acad. Press.

102 Véase Bertolini, E. (2011). La tutela dei diritti fondamentali in Giappone, Napoli, Jovene. 


\subsubsection{Derecho islámico}

Mientras que en los casos ahora mencionados ha habido compenetración al menos parcial entre constitucionalismo y Derechos diversos, una resistencia más clara se ha dado en el mundo islámico, o en parte del mismo, aunque, como siempre, también en estas regiones todos los Estados se han dado una constitución. En el Derecho islámico — explica M. Oliviero- la identificación entre religión y Derecho es teóricamente absoluta, y ello explica por qué todavía muchos Estados islámicos se definen como Estados teocráticos o confesionales, en tendencia opuesta a lo que prevalece en las democracias contemporáneas ${ }^{103}$. El islamismo — continua M. Oliviero- ha producido un Derecho (la Shari 'a) que se compone de cuatro elementos: la revelación divina que, a través del profeta Mahoma, se encuentra recogida en el Corán; la sunna, es decir, el conjunto de reglas (badit) extraídas, a través de la labor de los intérpretes, de las palabras y de las acciones del profeta, y también de la aprobación que el mismo había dado a propósito de hechos directa o indirectamente conocidos; la idjma, esto es, las reglas en torno a las cuales se ha formado el consenso de la doctrina jurídica y que por tanto se consideran conformes a la voluntad divina; el qiyas, o conjunto de reglas extraídas por analogía de las normas derivadas de otras fuentes. Por lo tanto, sobre la revelación divina ha venido a estratificarse un Derecho jurisprudencial elaborado fundamentalmente entre el siglo viI y el siglo x y que todavía hoy constituye el núcleo inmodificable del Derecho musulmán vigente.

Resultará más fácil comprender cómo puede encontrar aplicación en aquellos ordenamientos un Derecho cristalizado hace casi diez siglos si se tiene en cuenta que el Derecho musulmán tiene como contenido principalmente la materia privada y la penal; queda pues un cierto margen de acción para el Derecho público ${ }^{104}$. Sin embargo, el parcial o total fracaso de las llamadas primaveras árabes demuestra la dificultad de insertar los caracteres del constitucionalismo en estructuras sociales marcadas por el islamismo y la escasa identificación con el propio concepto de «Estado», cuyas

${ }^{103}$ Sobre el Derecho musulmán Castro, F. (2007). Il modello islamico, Torino Giappichelli; ID. (1989). Voz «Diritto musulmano e dei Paesi musulmani», Enc. giur., XI, Roma, Ist. enc. it., p. 1 ss.; ID. (1990). Voz «Diritto musulmano», Dig. priv., VI, Torino, Utet, p. 284 ss. Bibliografía actualizada sobre el Islam en IQBaL, M. (1989). The Reconstruction of Religious Thought in Islam, 2. ${ }^{a}$ ed., London, Oxford U.P.; De Wael, H. (1989). Le droit musulman. Nature et evolution, Paris, Cheam; NA'Im, A.A. (ed.) (2002). Islamic Family Law in a Changing World: A Global Resource Book, London, Zed Books; Kamali, M.H. (2008). Shari a Law: An Introduction, Oxford, Oneworld; Mallat, C. (2006). «Comparative Law and the Islamic (Middle Eastern) Legal Culture», en REImANN, M., ZimmermanN, R. (eds), The Oxford Handbook of Comparative Law, cit., p. 610 ss.; ID. (ed.) (1993). Islam and Public Law: Classical and Contemporary Studies, London-Dordrecht-Boston, Graham \& Trotman.

104 La necesidad de modernizar el Derecho musulmán ha sido perseguida a veces a través de procesos de laicización (Turquía y Estados musulmanes de la ex Unión Soviética); las más de las veces a través de sistemas normativos basados en la coexistencia del Derecho divino y del Derecho político: cfr. AzZIMAN, O. (1993). La traditionalisation du droit: tradition juridique islamique et droit privé marocain, Roma, CNRCentro st. e ricerche di dir. comp. e straniero, cuad. n. 11. 
fronteras fueran delimitadas por la colonización muchas veces sin ninguna conexión con otros criterios identificativos, como tribus, pueblos, etnias, tradiciones, estructuras de poder preexistentes, etc. ${ }^{105}$.

\subsection{Derecho socialista}

En el Estado socialista, las formas de producción normativa, coherentemente con el planteamiento teórico del marxismo-leninismo, derivan de la organización estatal y, por lo tanto, del Partido Comunista. Negada cualquier división de poderes, la suma de los mismos se concentra en manos de los órganos dirigentes del partido al cual pertenece, entonces, el primado sobre las fuentes. Desde esta perspectiva, la misma constitución no representa otra cosa que un mero balance descriptivo de las relaciones económicas y sociales instauradas y/o programadas ${ }^{106}$.

«La «Constitución socialista» es la ley fundamental que contiene los principios propios de la forma de Estado socialista, y que surge en oposición al moderno Estado de Derecho. Podrá ser una Constitución-resultado, tal y como fue enunciado por Stalin para la Constitución soviética de 1936, o una Constitución-programa (igualmente vinculante) como aquella leninista de 1918 de Rusia y, al menos en parte, también la brezneviana de la URSS de 1977, en donde, sin embargo, no se disponen limitaciones al poder. La Constitución socialista no es neutra, aun cuando sí coloca en sus cimientos la conquista del poder por parte de los trabajadores, la propiedad «socialista» y la garantía «material» de los derechos fundamentales, mas estos últimos debían ser considerados en función del socialismo y de los derechos económicos dispuestos antes de los derechos de libertad. Como contraposición a la división de los poderes establece el principio de la «unidad del poder estatal» con la subordinación de todos los órganos estatales a la asamblea representativa (los Soviet en Rusia-URSS) gracias también al corolario de la «doble dependencia», vertical y horizontal. La dirección del partido marxista-leninista, conforme a su orientación política, garantiza simultáneamente la coordinación de todos los órganos estatales y el principio de preferencia de los hechos sobre la teoría. Permanecen supeditados a la dirección del partido otros principios como la participación de los ciudadanos a las actividades estatales y la colegialidad de la dirección del Estado, que excluía en la URSS un Jefe de Estado monocrático» ${ }^{107}$.

Todos los Estados que han hecho o hacen referencia a las teorías socialistas se dotaron de una constitución. La matriz de las doctrinas subyacentes es, no obstante,

105 Sobre las transiciones y la denominada «primavera árabe» véase el número monográfico 11/2012 de la Rev. gen. der. públ. comp., titulado «El mundo árabe»; Aвbiate, T. (2016). La partecipazione popolare ai processi costituenti. L'esperienza tunisina, Napoli, Ed. Scientifica.

106 Véase AJani, M. (2008). Il modello post-socialista, 3a ed., Torino, Giappichelli.

107 Ganino, M. (2012). Voz «Constitución socialista», en PEgoraro, L. (ed.), Glosario de Derecho público comparado, cit., p. $51 \mathrm{~s}$. 
unitaria y diversa de la de las constituciones que se han alimentado antes de las doctrinas constitucionalistas. De nuevo, encontramos la aceptación del principio de constitución como documento básico del Estado, pero el rechazo de los contenidos típicos del liberalismo, y sobre todo una distinta axiología de las relaciones entre individuo y sociedad y una distinta percepción del papel del Estado.

\section{CONTRADICCIONES EN EL CONSTITUCIONALISMO Y FRACTURAS ENTRE CONSTITUCIONALISMO Y CULTURAS}

Los ejemplos arriba mencionados demuestran las resistencias y dificultades de integración entre Derechos tan distintos, y al mismo tiempo la anti-historicidad de las pretensiones hegemónicas del constitucionalismo, sea clásico o «neo». El hecho de que todos nosotros compartamos sus valores no implica que todos los otros los comparten, o cuanto menos que coloquen los distintos valores al mismo nivel axiológico que en Occidente. Al rechazo (no tanto de sus valores, sino de sus axiologías) concurren también las contradicciones en su interpretación en lo largo del desarrollo histórico.

La doctrina constitucionalista occidental ha formulado y sigue formulando conceptos y palabras a los que atribuye carácter de eternidad y de absolutismo espacial/temporal. Además de liberté, egalité, fraternitét ${ }^{108}$, se puede pensar en «democracia», con un sentido tán polisémico ${ }^{109}$, en "partecipación» ${ }^{110}$, «federalismo» ${ }^{111}$, «soberanía», etc. Como ya se ha dicho, no es capaz de estudiar e intentar comprender otros conceptos y palabras, que fundamentan otras culturas: no sorprende que haya tantas incomprensiones en el mundo, dado que más de 4.000 millones de personas viven su dimensión jurídica, además de social y cultural, justo con base en expresiones diversas.

Hasta el centro del significado moderno del constitucionalismo — «derechos»tiene lagunas y contradicciones: al hablar de «derechos fundamentales», y aunque los modelos circulen intensamente, solo o sobre todo el constitucionalista europeo continental tenderá a aferrarse a las teorías de la Ilustración, como también a la división de los poderes y a cuanto le sigue, diversamente de aquel británico, por no hablar de ordenamientos más lejanos. Ineludiblemente, el objeto de su estudio estará condicio-

108 Título del monográfico de la Rev. gen. der. públ. comp. n. 20/2017.

109 Reenvío a mi artículo (2014). «Costituzioni e democrazia: definizioni e classificazioni nel costituzionalismo contemporaneo», Rass. parl., aprile-giugno, p. 249 ss., y Rev. latino-am. est. const., n. 16, p. 121 ss.

110 Pegoraro, L., Bagni, S. (2014). «'Diritto’ a una buona amministrazione e principio di partecipazione», Confluenze, n. $6(2)$, p. 1 ss.

111 Pegoraro, L. (2016, 2016 y 2017). «Para una teoría integradora del federalismo y la plurinación». Federalismi.it, n. 19, p. 1 ss., en ID., Teoría y modelos de la comparación. Ensayos de Derecho constitucional comparado, Santiago-Chile, Olejnik, p. 325 ss., y en Estupiñán Áchury, L., PAVANI, G. (eds.), Plurinacionalismo y centralismo. Tensiones del Estado unitario en América Latina, Bogotá, Un. Libre, p. 31 ss. 
nado según el desarrollo en su ordenamiento de aquella «cosa» que está convencido de llamar «derechos», y que se bautiza con este apelativo. Sin embargo, dos tercios de la humanidad se basan en concepciones sociales que no derivan de los derechos individuales, sino - como se ha dicho varias veces — de la comunidad, o de la obligación interior, o por lo menos de visiones trascendentes de los individuos ${ }^{112}$.

El análisis de las constituciones pertenecientes a varios ciclos del constitucionalismo — desde aquellas más antiguas a las más recientes — y a las diversas regiones del mundo, demuestra la historicidad y la relatividad de la etiqueta (o sea: aquello que es fundamental para un ciudadano de Los Ángeles o de París no lo es para un indio de los Andes, y viceversa). Véase por ej. la Constitución de Bolivia (2008), que en su primera parte («Bases fundamentales del Estado. Derechos, deberes y garantías»), título II («Derechos fundamentales y garantías»), en el primer capítulo, no añade más, sino solo enumera los siguientes: a la «vida y a la integridad física, psicológica y sexual»; en particular para las mujeres, «a no sufrir violencia física, sexual o psicológica»; reiteradamente, en varios artículos, el «derecho al agua y a la alimentación»; el derecho a la «seguridad alimentaria, a través de una alimentación sana, adecuada y suficiente para toda la población» en conexión con los derechos a la salud, al hábitat, a una vivienda adecuada; el «derecho a recibir educación en todos los niveles de manera universal, productiva, gratuita, integral e intercultural, sin discriminación». Incluso, los derechos a «servicios básicos de agua potable, alcantarillado, electricidad, gas domiciliario, postal y telecomunicaciones» ${ }^{113}$. Si se considera también que, en el Este de Europa, con decisiones axiológicas muy distintas, algunas constituciones consideran fundamental el derecho a la herencia, la impresión es por tanto aquella de encontrarnos en presencia de una categoría evanescente.

Incluso el «derecho» considerado «absoluto» por excelencia — la vida— tampoco en los esquemas teóricos occidentales resiste a la supremacia de la sociedad («nación», «patria») cuando se decide una guerra ${ }^{114}$. Y con ello todos los otros

112 Vid. Pegoraro, L. (2009). «Direito constitucional comparado y uso conotativo dos direitos (e dos adjetivos que o acompanham)». Rev. bras. est. const. — RBEC, n. 12, p. 93 ss., trad. esp. (2010 y 2012). «Derecho Constitucional Comparado y uso connotativo de la palabra 'derechos' (y de los adjetivos que la acompañan)». An. iberoamer. der. const., n. 14, p. 347 ss., y en GonZÁlez PlacenCia, L., Morales SÁnCHEZ, J. (eds), Derechos Humanos en perspectiva: actualidad y desafíos en el siglo XXI, 2 volúmenes, México, Fontamara, I, p. 39 ss., trad. it. (2013). «Diritto costituzionale comparato e uso connotativo di 'diritti' (e degli aggettivi che li accompagnano)», en AA.Vv., Studi in onore di Claudio Rossano, 4 volúmenes, Napoli, Jovene, I, p. 421 ss.

113 Además, configurados al contrario a través de prohibiciones: «Nadie será torturado, ni sufrirá tratos crueles, inhumanos, degradantes o humillantes. No existe la pena de muerte»; «Ninguna persona podrá ser sometida a desaparición forzada», $\mathrm{y}$ «Ninguna persona podrá ser sometida a servidumbre o esclavitud». En fin, como obligación para el Estado, «prevenir, eliminar y sancionar la violencia de género y generacional, así como toda acción u omisión que tenga por objeto degradar la condición humana, causar muerte, dolor o sufrimiento físico».

114 Véase Fonseca, D. (2017). «Parler du terrorisme. Une approche philosophique». Rev. gen. der. públ. comp., n. 21, p. 1 ss. 
derechos. En particular, la limitación de los derechos es muy utilizada contra los ciudadanos extranjeros: la legislación de Estados Unidos ha logrado «administrativizar» los procedimientos contra los extranjeros considerados sospechosos, a través de la suspensión (no judicial) de los derechos y garantías procesales hasta casi dos años; el ordenamiento británico permite en todo caso la detención (sin habeas corpus) hasta 28 días $^{115}$. La privacy — the right to be let alone- desapareció en todo el Occidente a favor del control cotidiano del Estado, de entidades públicas y privadas, realizando, no ya en el mundo del socialismo real, como imaginaba Orwell, sino en las liberal-democracias, la pesadilla del Gran Hermano. La opinión pública, por su parte, asustada por la escasa definición del «enemigo», en su mayoría apoya las políticas de limitación, y la idea de que la seguridad es un valor absoluto ${ }^{116}$.

Finalmente, cuando un concepto forjado (también) por las doctrinas políticas occidentales se vuelve incómodo — como «fraternidad»- simplemente se ignora, se pretende que no existe. Lo mismo pasa para «no taxation without representation», verdadero pilar de nuestro constitucionalismo, sacrificado en el altar de la ciudadanía, de la soberanía, de la seguridad ${ }^{117}$. Con evidencia, los migrantes extranjeros no son seres «humanos», y no se contesta la clara contradicción entre «derechos humanos» y «ciudadanía».

A nivel doctrinal, el a priori iusnaturalista, la elección del campo ideológico, la opción investigativa no favorecida por categorías científicamente elaboradas conduce al «choque de civilizaciones», del cual razona Huntington ${ }^{118}$, no a través del análisis científico, pero sí a través de la renuncia consciente o inconsciente de realizar estudios con un método. Con el resultado, no solo de producir investigaciones construidas con arena, sino también de avalar a quien con las investigaciones apoya operaciones de exportación de valores, así como supraestructuras culturales para imponer nuevos

115 Ley de Terrorismo de 2006 y otras leyes y decretos precedentes. Véase Sciullo, N.J. (2012). «On the Language of (Counter)Terrorism and the Legal Geography of Terror», Willamette L.R., n. 48, p. 317 ss.

116 Sobre la seguridad como bien social y la jurisprudencia ponderativa adoptada por las Cortes Constitucionales v. Rosenfeld, M. (2006). "Judicial Balancing in Times of Stress: Comparing the American, British and Israeli Approaches to the War on Terror», Cardozo L.R., n. 27, p. 2079 ss. Sobre la seguridad como «derecho», IsEnseE, J. (1983). Grundrecht auf Sicherheit, de Gruyter, Berlin-New York, y la premisa crítica a la edicción en italiano de FENUCCI, T. (2017). Il diritto fondamentale alla sicurezza. A proposito dei doveri di protezione dello Stato liberale di diritto, Napoli, Ed. Scientifica, titulada «Alcune considerazioni sul diritto fondamentale alla sicurezza».

117 Núñez Torres, M.G., Cavazos Guajardo Solís, A. (2017). «El principio de no taxation without representation, la migración y su impacto en los ordenamientos jurídicos latinoamericanos». Rev. gen. der. públ. comp., n. 20. Sobre este asunto, el 7 de noviembre 2016 se celebró un Congreso organizado por la Universidad de Milán, Departamento de Derecho público italiano y supranacional, con la colaboración del Centro de Estudios sobre América Latina de la Universidad de Bolonia, «No hay tributación sin representación - No taxation without representation- Ser migrante en el contexto italiano, europeo, latinoamericano».

118 Huntington, S.P. (1996). The Clash of Civilizations and the Remaking of World Order, New York, Simon \& Schuster, trad. it. (2000). Lo scontro delle civiltà e il nuovo ordine mondiale, Milano, Garzanti. 
órdenes globales insensibles a cualquier historia, a cualquier cultura, a cualquier sociedad, y a cualquier civilización ${ }^{119}$.

La doctrina intenta dar nuevas lecturas globales de los fenómenos, buscando los elementos unificadores. «Comparison becomes the law» — diría P. Goodrich ${ }^{120}$. Las nuevas teorías parten empero desde arriba, como el neoconstitucionalismo, y no del análisis empírico ${ }^{121}$. En suma, viene antes la individualización de los elementos irrenunciables (dignidad, persona, procesalismo, derechos humanos, etc.), propuestos en clave occidental, y luego su aplicación en los casos. La «irresistible expansión del constitucionalismo», subrayada por casi todos los estudiosos, existe también porque la doctrina apoya la idea de su superioridad respecto a otras formas de organización constitucional (en sentido sustancial). Hay quien dice que el Derecho constitucional es solo el occidental. El resultado a veces es el uso de parámetros no reales (recte, extraídos de la realidad) sino ideales. La comparación tiene así una función extrínsecamente ética en lugar de científica, ética intrínsecamente.

La muerte del Derecho comparado en el mundo globalizado, que se encuentra en las visiones de Fukuyama ${ }^{122}$, es un refrán común ${ }^{123}$ : el riesgo es que la globalización

119 La expansión geopolítica del constitucionalismo — a menudo a nivel meramente epidérmicoconlleva un crecimiento paralelo de las investigaciones al respecto. Pero a la grosería de la conquista a menudo se une una igual superficialidad en el análisis doctrinal de los fenómenos: el «imperialismo cultural», que reconduce a las categorías occidentales los elementos de culturas distintas, tiene efectos también en las traducciones (y clasificaciones), como consecuencia de la poca atención hacia las otras culturas. Cfr. Pegoraro, L., Rinella, A. (2018). Derecho constitucional comparado, 2, Sistemas constitucionales, cit., tomo A, p. 38 ss.

${ }^{120}$ Goodrich, P. (2012). «Interstitium and non-law», en Monateri, P.G. (ed.), Methods of Comparative Law: An Intellectual Overview, Cheltenham-Northampton, Elgar, p. 229.

121 Para un ejemplo de investigación «comparada» desde arriba, v. CASSESE, S. (2016). «Sulla diffusione nel mondo della giustizia costituzionale. Nuovi paradigmi per la comparazione giuridica», en Bagni, S., Nicolini, M., Palici di Suni, E., Pegoraro, L., Procida Mirabelli di Lauro, A., SERIO, M. (eds), Giureconsulti e giudici. L'influsso dei professori sulle sentenze, I, Le prassi delle Corti e le teorie degli studiosi, Torino, Giappichelli, p. 84 ss. Sobre el neoconstitucionalismo vid. supra, $§ 2.3$. Un análysis crítico en VAladés, D. (2017). «Los constitucionalistas y el cambio constitucional», en BAZÁN, V., Castro Rivera, E., Cuarezma Terán, S.J. (eds), Estado constitucional y convencional, Managua, Inej.

122 Parece utópica la visión de Funuyama, F. (1989). «The End of History?», The National Interest, n. 16, p. 3, que "What we may be witnessing is not just the end of the Cold War, or the passing of a particular period of post-war history, but the end of history as such: that is, the end point of mankind's ideological evolution and the universalization of Western liberal democracy as the final form of human government».

123 Véase Siems, M. (2007). «The End of Comparative Law». Journ. comp. law, n. 2 (2), p. 133 ss. Y (recordado por el mismo Siems) ReimanN, M. (1996). "The End of Comparative Law as an Autonomous Subject», Tulane eur. and civil law forum, n. 11, p. 49 ss.; además, GoODRICH, P. (2012). «Interstitium and Non-Law», cit., p. 227: «If there is a modus, a method and melody to the angst of comparative law, a theme that conjoins the grand and merry men of situated difference, it is that of the singular universal, the unhappy consciousness of the particular instance. As thus staged, the problem with comparison is not the comparata but rather, and this will be my thesis here, my emblem and end, it is the collapse of law. The agony of indistinction, the erasure of boundaries, the becoming virtual of borders and identities spells the universalization of comparison and the advent of non-law». 
anule las diferencias, y por ello la ciencia comparada esté destinada a morir, como varios imaginan en virtud de su irrelevancia de cara a fenómenos como la convergencia transnacional y la llamada armonización y progresivo alcalce de un Derecho común $^{124}$. En particular, la globalización erosiona la idea misma de Derecho: caen las barreras entre público y privado, y éste se sustrae a los imperativos de Westfalia y a las reglas de un Derecho internacional que vale, allí donde vale, solo para lo público; el soft-law deja márgenes abiertos; ni las fuentes privadas ni las públicas consiguen regular la actividad de actores privados en la economía global ${ }^{125}$. Pero el miedo es probablemente infundado si solo se considera la refractariedad al cambio generada por las resistencias de las culturas jurídicas (y de las culturas en general), y — con consecuencias importantes en ámbito constitucional — la reivindicación de modelos de organización constitucional alternativos al occidental ${ }^{126}$.

124 Sobre el debate, Muir Watt, H. (2006). «Globalization and Comparative Law», en Reimann, M., Zimmermann, R. (eds), The Oxford Handbook of Comparative Law, cit., p. 579 ss., subraya el nexo entre papel de la comparación en el mundo globalizado y los esfuerzos para uniformizar empezados en el siglo xx, desde el Congreso de París (p. 581), preguntándose si la comparación será todavía posible en el mundo globalizado (p. 583 ss.). Véase también Pfersmann, O. (2001). «Le droit comparé comme interprétation et comme théorie du droit». Rev. int. dr. comp., n. 2, p. 277: «S'il n'existe qu'un seul, le problème ne se pose pas, s'il en existe plusieurs, la solution proposée (un système transnational et par conséquent unique) est par hypothèse exclue», y SiEms, M. (2007). «The End of Comparative Law», cit., p. 133 ss., donde anticipa el fin del Derecho comparado como materia académica. [Contra, Costantini, C. (2012). «The Iconicity of Space: Comparative Law and the Geopolitics of Jurisdictions», en Monateri, P.G. (ed.), Methods of Comparative Law, cit., p. 230: «Comparative law is not at its intellectual end».] Criticando las supuestas leyes universales (teológicas como jurídicas), y en diálogo con Agamben, G. (2008) — citado en la ed. francesa Le Régne et la gloire, Paris, Seuil, p. 56 ss.—v. Goodrich, P. (2012). «Interstitium and Non-Law», cit., p. 225 s.: «There is a system of legality, a purportedly universal law, a mythology associated with modernity and the West that believes that God and law are unitary, One, and should logically therefore proceed ad similia, towards the same, as a brotherhood, identified and identifying only with and in respect of similarity and the singularity of the Cross. That is a somewhat reductive reading, and as Agamben nicely shows, the doctrine of the Trinity, of a triune deity, in fact absorbs an element of polytheism into the grand schema and penetrative mode of Christian law». Véase también el análisis de CAssese, S. (2009). Il diritto globale, Torino, Einaudi; ID. (2003). Lo spazio giuridico globale, Roma-Bari, Laterza. Por último, Legrand, P. (2006). «How to Compare Now», Legal st., n. 2, p. 232 ss.

${ }_{125}$ Muir Watt, H. (2012). «Further Terrains for Subversive Comparison: The Field of Global Governance and the Public/Private Divide», en Monateri, P.G. (ed.), Methods of Comparative Law, cit., p. 270 s. y espec. p. 274: «Thus, neo-liberalism requires and induces 'désordre public' or privateinterest-driven public policy — in fact a scheme of governance that is a far cry from its liberal predecessor; but its basic tenets are made to appear to fit into a spontaneous continuum, leading as if quite naturally to the neutralization of those checks, balances and other mechanisms of self-restraint, which, in the liberal model, subordinate private interests to those of the polity». En la doctrina italiana, más recientemente, ANDò, B., VeCCHIO, F. (eds) (2012). Costituzione, globalizzazione e tradizione giuridica europea, Padova, Cedam; en la española v. Bustos GisBert, R. (2005). La Constitución red: un estudio sobre supraestatalidad y Constitución, Bilbao, Ivap.

126 Para Samuel, G. (2004). "Epistemology and Comparative Law: Contributions from the Sciences and Social Sciences», en VAN Hoecke, M. (ed.), Epistemology and Methodology of Comparative Law, Portland, Hart, p. 35 ss., el common law está más preparado para afrontar los retos de la complejidad 


\section{LA ENSEÑANZA DE ALGUNAS EXPERIENCIAS SINCRETISTAS}

¿Cómo puede la cultura disociarse del brutal positivismo de la fuerza y del objetivo que, paradójicamente en nombre de visiones iusnaturalistas, pretende imponer como absolutos valores que por el contrario se han generado gracias a costosas conquistas históricas? ¿Cómo puede la cultura favorecer el respeto por las culturas (a saber: por la autodeterminación para que cada pueblo se dé y guarde su cultura), y el respeto de cada comunidad cultural, incluso dentro de los límites de los ordenamientos liberales-democráticos?

La respuesta no llega del modelo islámico, ni tampoco del socialista, casi eliminado por la historia. China, Japón e India sugieren soluciones sincretistas, aunque en parte bipolares (o esquizofrénicas), marcadas por fracturas profundas entre Derecho público y privado, Derecho formal y Derecho viviente, justicia estatal y justicia tradicional, forma y sustancia, doctrina, jurisprudencia y legislación, y sobre todo cultura y formante legal.

La respuesta quizás llegue de países que la doctrina occidental mira a menudo con desprecio, por no decir la política ${ }^{127}$. Son los que antes hemos recordado porque en el marco de un constitucionalismo de origen occidental han incorporado, posivizándolos y parametrizándolos, principios pertenecientes a la tradición, la filosofía, las creencias y tradiciones.

No son incompatibles con la tradición occidental. Nos recuerda Silvia Bagni: «la tesis que apoyo es que la renovación de la ciencia jurídica comparada debe pasar por la inclusión del Amor en la aplicación del método. Para evitar una fácil hilaridad o juicios a priori despreciativos, es oportuno recordar cómo el léxico sentimental ha sido básico en la elaboración del constitucionalismo: sería posible incluso empezar citando a la eudaimonia aristotélica como finalidad de la actividad política, y luego, centrándose en los orígenes históricos del constitucionalismo, recordar la búsqueda de la felicidad como unalienable right en la Declaración de Independencia estadounidense y la fraternidad en la revolución francesa, hasta llegar al nuevo constitucionalismo latinoamericano, que incluye el sumak kawsay, cosmovisión kichwa traducida en castellano por «buen vivir», como valor, principio y estatuto de derechos en las Constituciones ecuatoriana y, en versiones similares, en otros ordenamientos del constitucionalismo contra-hegemónico, como por ej. el ubuntu en la jurisprudencia constitucional del Sudáfrica o el Gross National Happiness de la Constitución de Bhután ${ }^{128}$. Norberto Bobbio en Il futuro della

respecto al civil, pues es el producto de una cultura a-científica. Un análisis profundo se encuentra en Somma, A. (2014). Introduzione al diritto comparato, Roma-Bari, Laterza, cap. 2, § 3.

${ }^{127}$ La referencia es a la famosa frase de Donald Trump que define «letrina» algunos países del Sur del mundo.

${ }^{128}$ BAGNI, S. (2017). «Fraternidad como principio epistemológico del derecho constitucional interno y comparado». Rev. gen. der. públ. comp., n. 20, y bibliografía sub notas 65 y 66. Para un análisis del impacto de las investigaciones sobre la felicidad en las elecciones de política del Derecho cfr. HuANG, P.H. (2010) «Happiness Studies and Legal Policy». Annual rev. of law and soc. sc., n. 6, p. 405 ss. 
democrazia, identificaba la tolerancia, la no violencia y la fraternidad como los valores básicos de la democracia, afirmando que la democracia podía devenir un «hábito mental» solo si se iluminaba por el espíritu de fraternidad que une a los hombres» ${ }^{129}$. El distinguido filósofo y jurista Gustav Radbruch — sigue recuerdando Bagniescribía sobre la ciencia del Derecho: «Pero el derecho, mientras toca superficialmente, por así decirlo, la viva alma del hombre, como fuente de importancia secundaria de sus acciones relevantes solo jurídicamente, se aleja de la única cosa necesaria. Es la esencia y el pecado mortal del derecho y de sus representantes, "creer que haya relaciones en las que se pueda interactuar con un hombre sin amor, pero estas relaciones no existen" ${ }^{130}$.

«Los Países latinoamericanos, juntos con otros que igualmente podrían ser incluidos en la familia del constitucionalismo contra-hegemónico, como Buthán, India ${ }^{131}$ o Sudáfrica, incluyendo quizás las transiciones realizadas en el Magreb y algunos casos asiáticos, están laboriosamente construyendo una nueva forma de Estado, democrático, social e intercultural. No creo que sea un caso en el que sus instituciones utilicen frecuentemente referencias extranjeras comparadas en la construcción de sus propios ordenamientos jurídicos. Igualmente, no creo que sea por casualidad que sus tradiciones culturales autóctonas estén impregnadas de valores comunitarios y solidarios. La constitucionalización de la fraternidad deriva en muchos casos de la recepción del criptotípo cultural indígena que, en sus varias formas (sumak kawsay, ubuntu, budismo, solo para hacer algunos ejemplos) incluye el deber de tratar a los otros como hermanos, a los avis y a las futuras generaciones come si fuesen presentes».

Pasan, estos países, del multiculturalismo al interculturalismo ${ }^{132}$, enseñando a Europa y al mundo anglosajón algunas nuevas coordenadas para encontrar denominadores comunes entre distintas culturas.

Berndt Marquardt contrasta la idea que América Latina represente algo «menos» de Europa, un mero (y malo) receptor de instituciones forjadas en el Continente viejo, debido al influjo de algunas preconcepciones por parte de la doctrina europea y

129 BobBio, N. (2010). Il futuro della democrazia, Milano, RCS, p. 38: « ¿puede volverse costumbre sin el reconocimiento de la fraternidad que une a todos los hombres en un destino común?».

130 Radbruch, G. (1958). Einführung in die Rechtswissenschaft, Stuttgart, Koehler, trad. it. (1961). Introduzione alla scienza del diritto, Torino, Giappichelli, p. 81 s.

131 Amirante, D. (2014). Lo Stato multiculturale, cit.

132 Véase BAGNi, S. (2017). «Estudio introductorio sobre el deslinde conceptual del estado intercultural», en ID. (ed.), Lo Stato interculturale: una nuova eutopia? — The Intercultural State: a New Eutopia? - El Estado intercultural: ¿una nueva eutopía?, en Bologna: Dipartimento di Scienze giuridiche, https://amsacta.unibo.it. DOI: http://doi.org/10.6092/unibo/amsacta/5488, e ID., (2017). «Lo Stato interculturale: primi tentativi di costruzione prescrittiva della categoria», en BAGNI, S., FIGUEROA Mejía, G., Pavani, G. (eds), La ciencia del derecho constitucional comparado, cit., II, p. 111 ss. Véase también Pegoraro, L. (2017 y 2018). «América Latina como categoría y objeto de comparación (Coordinadas metodológicas para el estudio comparado de los sistemas jurídicos latinomaericanos)». Dir. pubbl. comp. eur., n. 1, p. 81 ss., y Pensamiento const., n. 22, p. 175 ss. 
norteamericana ${ }^{133}$. Sin embargo, en el análisis de las causas de tal enfoque, individualiza algunas caracteristicas de Latinoamérica que podríamos utilizar para subrayar ulteriores elementos «criptotipicos» comunes del área. En particular, en el formante doctrinal, aunque no solo, «En términos de psicología social, se debe advertir una autoestima relativamente baja que puede denominarse el victimismo... ${ }^{134}$.

Destaca en estas frases la gran responsabilidad de la doctrina académica constitucionalista, y el enlace entre economía, política y academia, la cual última ofrece soporte, en nombre de los derechos humanos y la democrácia, a operaciones económicas y políticas que tienen objetivos bién distintos.

Las culturas orientales «no comparten la creencia en la naturaleza aislada, atomista y competitiva del ser humano, ni en la naturaleza utilitarista del homo economicus, ni en el modelo social de centrifugación y gravitación, ni en la naturaleza absolutamente racional del hombre, ni en la naturaleza laica del mismo, ni en la naturaleza idéntica de los géneros, ni en las libertades sin virtudes, ni en el enfoque materialista y hedonista de la vida» ${ }^{135}$. América Latina, de modo diferente a Asia y África, no rechaza todos los valores (o si quieren disvalores) de la cultura occidental; mejor, solo la percepción indígena puede ser paragonada a las culturas africanas o asiáticas, pero por lo demás el «sistema» se propone como gran elemento de reequilibrio entre culturas tan distintas: el nuevo constitucionalismo latinoaméricano aparece entonces también como un mestizaje cultural, que traduce a nivel jurídico el mestizaje «físico» que caracteriza buena parte del continente.

133 Marquardt, B. (2016). Historia constitucional comparada de Iberoamérica. Las seis fases desde la Revolución de 1810 hasta la transnacionalización del siglo XXI, Bogotá, Ibañez, p. 56 ss., detenendose sobre la influencia del primer-tercier-mundismo hegemónico, habla de «la mirada desdeñosa de las ciencias europeas y norteaméricanas hacia América Latina».Véase también J.H. ElliotT (1970). The Old World and the New 1492-1650, Cambridge, Cambridge U.P., trad. esp. (1972). El Viejo Mundo y el Nuevo, Alianza, Madrid.

134 Marquardt, B. (2016). Historia constitucional comparada de Iberoamérica, cit., p. 54, citando a Lomné, G. (2009). "Latinoamérica tiene un déficit de autoestima», entrevista de F. Tafur en $U N$ Periódico, n. 129, Bogotà, Unal, p. 9. Un síntoma de este fenómeno denunciado por Marquard lo he destacado en un escrito reciente, debatiendo y criticando la «adoración» de la academia latinoaméricana a la academia europea y norteamericana, acogida sin una actitud crítica como «argumentum quoad auctoritatem». Piénsese sólo en las innumerables citas — por parte de la doctrina y la jurisprudencia- de autores como Häberle, Ferrajoli, Dworkin, Zagrebelsky, y otros que proponen teorías neoconstitucionalistas, de un lado, o de otro lado a las de Kelsen, Bobbio, Guastini, Bökenförde, etc., por parte de quienes adhieren a las escuelas positivistas y realistas. Remito a mi artículo (2015 y 2017). «Ruolo della dottrina, comparazione e "legal tourism”». Diálogos de Saberes, n 43, p. 219 ss., y en AA.Vv. Un giurista di successo. Studi in onore di A. Gambaro, 2 volúmenes, Milano, Giuffrè, I, p. 317 ss. La cuestión es común: véase por ej. Andrés Botero, B. (2012). «La interpretación constitucional en América Latina. Una denuncia del colonialismo cultural en la dogmática constitucional contemporánea», en Barbosa Delgado, F.R. (ed.), Historia del derecho público en Colombia, Bogotá, Un. Externado, p. 319 ss., y además la crítica del propio MARQUARD, B. (2016). Historia constitucional comparada de Iberoamérica, cit., p. 47, notas 144 ss., a Häberle pero también a los autores latinoaméricanos.

135 Marquard, B. (2016). Historia constitucional comparada de Iberoamérica, cit., p. 39. 
Todo eso, sin embargo, como bien destaca Marquard, aparece desconocido no solo a la ciencia constitucionalista clásica de Estados Unidos (donde los profesores de Derecho constitucional ni siquiera conocen en su mayoria el Derecho constitucional europeo, y piensan que el mundo se acaba en Nueva York y Los Ángeles); no solo a la academia de Europa, sino también a un sector consistente del constitucionalismo latinoaméricano, absorto acritícamente en la contemplación de los modelos estadounidenses o europeos y su universalismo antihistórico, totalizante y uniformizador.

Se trata de una doctrina que de desde 1530 no ha avanzado un paso, parándose en la «cédula» de Carlos V evocada por S. Lanni ${ }^{136}$, con la cual se establecía que «los gobernadores, y justicias reconozcan con particular atención la orden, y forma de vivir de los indios, policía, y disposición en los mantenimientos, y avisen a los Vicerreyes, o Audiencias, y guarden a sus buenos usos, y costumbres en lo que no fueren contra nuestra sagrada religión».

La doctrina de los «cultos permitidos» en las constituciones del siglo XIX $^{137}$, que ha atravesado los siglos hasta ahora, se ha convertido en una doctrina acrítica de los derechos humanos propuesta por casi todos los «legal tourists» que pretenden universalizar los conocimientos del pueblo donde viven ${ }^{138}$, y también por los receptores pasívos que la aceptan sin plantear el dilema de la diversidad ${ }^{139}$.

En particular, quiero recordar la enseñanza del Continente acerca la exportación a otros sistemas de las soluciones escogidas acerca de las relaciones entre culturas distintas. América Latina, junto a África Austral y algunos países de Asia, parece haber emprendido un camino opuesto y de parcial resistencia a los fenómenos de la globalización. Considerada por siglos como un emblema de homogeneización económica y cultural por parte de Europa y los Estados Unidos, experimenta desde hace tiempo soluciones originales, por un lado, redescubriendo y tutelando las antiguas raíces, y por otro, proponiendo estructuras jurídicas no siempre coherentes con los

136 Lanni, S. (2016). Voz «Sistema giuridico latinoamericano». Dig. priv., Sez. civ., Agg., Torino, Utet, p. 720.

${ }_{137}$ V. por ej. Const. Grecia del 1864: «1. La religión dominante en Grecia es aquella de la Iglesia oriental ortodoxa de Cristo. 2. Las otras religiones son reconocidas y toleradas y la libertad de culto de su ejercicio protegida por la ley, pero el proselitismo está prohibido, como cualquier otro acto contrario a la religión»; Const. Portugal del 1826, art. 6: «La religión católica, apostólica y romana continuará siendo la religión del Reino. Todas las demás religiones serán permitidas a los extranjeros, con su culto doméstico y particular, sin ninguna forma exterior de templo»; Estatuto Albertino, art. 1: «La Religión Católica, Apostólica y Romana es la única religión del Estado. Los otros cultos que ahora existen son tolerados de conformidad con las leyes».

${ }^{138}$ La alusión es al Frankenstein de Mary Shelley (1818): «How dangerous is the acquirement of knowledge and how much happier that man is who believes his native town to be the world, than he who aspires to be greater than his nature will allow».

139 Por supuesto, uso aquí el término «legal tourism» en sentido distinto de CHen Lei (2012). «Contextualizing legal transplant: China and Hong Kong», en Monateri, P.G. (ed.), Methods of Comparative Law, cit., p. 192, donde es sinónimo de «transposition», «borrowing», «migration», «cross fertilization». 
patrones liberal-democráticos, alimentados por doctrinas conformistas y poco atentas a la diversidad.

¿Pueden las soluciones acerca del balanceo entre el Derecho tradicional y el de derivación estatal, cultura occidental y cultura indígena, armonía e individualismo, individuo, comunidad y naturaleza, elaboradas en América Latina, África y Ásia, ser exportadas a lugares y regiones donde se plantean, aunque de forma distinta, problemas análogos de compatibilización?

En Latinoamérica se trató, en años recientes, de reconocer — a nivel jurisprudencial, luego legislativo y constitucional - no solo los derechos individuales y comunitarios de los pueblos indígenas, sino de incorporar sus valores (su Grundnorm, podríamos decir) en el parámetro constitucional. Dejando al lado Estados Unidos, donde el problema se solucionó con el genocidio y la marginalización de los nativos sobrevivientes ${ }^{140}$, en Europa el choque es debido no a las reivindicaciones de comunidades pre-existentes, sino a la llegada de nuevas comunidades culturales, anómalas respecto a la cultura europea. Pese de la diversidad de presupuestos, a mi parecer, ello no impide aprender de América Latina, África y Asia las solucciones propuestas en busca de un distinto equilibrio entre valores desiquilibrados en Occidente, privilegiando el individualismo, en detrimento del comunitarismo y ecologismo; y privilegiando la libertad de los particulares, en detrimento de la igualdad y la fraternidad, aunque los tres séan considerados paritariamente en el tríptico revolucionario ${ }^{141}$.

En los juristas que estudian estos temas sin presunción y arrogancia se puede confiar porque, amándolo ${ }^{142}$, soportan culturalmente la exportación de un modelo de constitucionalismo «altruista» ${ }^{143}$ y respetuoso que pueda circular y afirmarse en otros lugares del mundo. Junto a Sudáfrica, Madagascar, Namibia, Botswana, Buthan, América Latina puede fertilizar el constitucionalismo mundial, retomando valores perdidos de equilibrio entre factores distintos — el individuo, la comunidad, la naturaleza; los derechos y los deberes; y la libertad, la igualdad, la fraternidad- propios

${ }^{140}$ Como es sabido, en Canada la First Nation (los indios nativos e inuit) tuvo un tratamiento jurídico distinto al que se practicaba en Estados Unidos. Cfr. TodD, R. (2001). Aboriginal People and Other Canadians, Ottawa, Un. of Ottawa Press; Miller, J.R. (2009). Compact, Contract, Covenant: Aboriginal Treaty-Making Power in Canada, Toronto, Toronto U.P.; en la doctrina italiana OlivetTi Rason, N. (2014). «Il patrimonio multiculturale dei canadesi»; ID. (2014). «Remarks on the Idea of "Aboriginal Peoples of Canada"», ambos en ID., Scritti 2005-2012, Padova, Cleup, p. 151 ss. y p. 247 ss.

141 Véase el número especial de la Rev. gen. der. comp., n. 20, 2017, dedicado a «Liberté, egalité, fraternité», y, acerca de la comparabilidad de Latinoamérica con Europa a este respecto, TONIATTI, R. (2017).«Il paradigma costituzionale dell'inclusione della diversità culturale in Europa e in America latina, cit., III, p. 1445 ss. y espec. p. 1477.

142 Véase Bagni, S. (2016). "All you need [to compare] is love», en ID. (ed.), El constitucionalismo por encima de la crisis. Propuestas para el cambio en un mundo (des)integrado, Filodiritto, Bologna, p. 10 ss.; ID. (2017). «Fraternidad como principio epistemológico del derecho constitucional interno y comparado», cit.; ID. (2017). «Comparative Law and ... Love: contro la globalizzazione del diritto, per la globalizzazione del giurista». An. dir. comp. st. leg. 2017, p. 47 ss.

143 Carducci, M. (2003). Por um Direito Constitucional Altruísta, cit. 
de muchas culturas autóctonas, pero también del cristianismo, del liberalismo revolucionario, del socialismo ${ }^{144}$.

Title:

Constitutionalization of Law and Constitutional Culture

\section{Summary:}

1. Defining the relevant lexical items. - 1.1. «Law». - 1.2. «Constitution». - 1.3. «Constitutionalism».- 1.4. «Legal Culture» and «Constitutional Culture». - 2. Constitutionalising the Law. - 2.1. Civil codes; or: the «constitutions» of the bourgeois. - 2.2. Disseminating the constitutions and constitutionalism. - 2.3. Constitutionalism under siege: the challenges of neo-constitutionalism. - 3. Incorporating Traditional Law: formal constitutionalism and its rejection. - 3.1. The resilience of legal traditions. - 3.2. Religious Law. - 3.2.1 Hindu Law. - 3.2.2.- Confucianism. - 3.2.3. Japanese Law. - 3.2.4. Islamic Law. - 3.3. Soviet Law. - 4. Cleavages between constitutionalism and culture. - 5. Law and culture: the legacy of their syncretism.

\section{Resumen:}

El ensayo analiza las dificultades que se encuentran a la hora de exportar los principios del constitucionalismo donde la cultura «constitucional» es diferente a la occidental. Además de denunciar las contradicciones internas y el abandono de algunos principios clave que lo inspiraron (desde «no taxation without representation» a «fraternité»), y el ataque a la misma idea de constitución por parte del neoconstitucionalismo, se centra en las características de algunas concepciones del Derecho antitéticas al constitucionalismo, o que proponen diferentes axiologías de valores. En particular, señala que algunas experiencias recientes basadas en la constitucionalización de las tradiciones proponen soluciones compatibles con las occidentales, de las cuales acentúan algunas características latentes.

${ }^{144}$ Una síntesis de tales valores, aunque con composiciones y colocaciones distintas, es la base incluso de la Resistencia europea al nazi-fascismo, como resulta claramente en las Lettere dei condannati a morte della Resistenza europea, editadas por Malvezzi, P., Pirelli, G. (1963), Torino, Einaudi: cfr. Pegoraro, L. (2015). «Diritto costituzionale e resistenza. Una breve rilettura attraverso le lettere di condannati a morte (e le canzoni partigiane)». Ann. dir. comp. st. leg. 2015, p. 521 ss. 


\begin{abstract}
:
The article analyses the difficulties to export the principles of constitutionalism where «constitutional» culture is different from the Western one. In addition, it aims to underline internal contradictions and the abandonment of some key principles that inspired it (such as «no taxation without representation» to «fraternité»), as well as the attack on the core vaules of the constitution by the so called «neoconstitutionalism». It then focuses on the characteristics of some conceptions of the law that are deemed to be antithetical to constitutionalism, or that propose different axiologies of values. In particular, the study points out that some recent experiences based on the constitutionalisation of traditions do offer solutions compatible with the Western ones, by emphazising some latent features.
\end{abstract}

\title{
Palabras clave:
}

Constitución; constitucionalismo; culturas jurídicas; cultura constitucional; tradición.

Key words:

Constitution; constitutionalism; legal cultures; constitutional culture; tradition. 